\title{
Current Research on Microbe-Plastic Interactions in the Marine Environment
}

\author{
Mira Latva ${ }^{1}$, Vinko Zadjelovic ${ }^{1}$ \& Robyn J. Wright ${ }^{2}$ \\ ${ }^{1}$ School of Life Sciences, University of Warwick, UK \\ ${ }^{2}$ Department of Pharmacology, Faculty of Medicine, Dalhousie University, Nova Scotia, Canada \\ robyn.wright@dal.ca
}

\begin{abstract}
The microbial colonisers of plastics - the 'plastisphere' - can affect all interactions that plastics have with their surrounding environments. While only specifically characterised within the last 10 years, at the beginning of 2021 there were 140 primary research and 65 review articles that investigate at least one aspect of the plastisphere. We gathered information on the locations and methodologies used by each of the primary research articles, highlighting several aspects of plastisphere research that remain understudied: (i) the non-bacterial plastisphere constituents; (ii) the mechanisms used to degrade plastics by marine isolates or communities; (iii) the capacity for plastisphere members to be pathogenic or carry antimicrobial resistance genes; and (iv) meta-OMIC characterisations of the plastisphere. We have also summarised the topics covered by the existing plastisphere review articles, identifying areas that have received less attention to date - most of which are in line with the areas that have fewer primary research articles. Therefore, in addition to providing an overview of some fundamental topics such as biodegradation and community assembly, we discuss the importance of eukaryotes in shaping the plastisphere, potential pathogens carried by plastics and the impact of the plastisphere on plastic transport and biogeochemical cycling. Finally, we summarise the future directions suggested by the reviews that we have evaluated and suggest other key research questions.
\end{abstract}

\section{Keywords}

Plastisphere; Plastic biofilms; Microbial communities; Marine plastic pollution; Plastic biodegradation 


\section{Introduction}

The quantity of plastic pollution entering the oceans annually is increasing year-on-year ${ }^{1}$, but the ultimate fate and durability of plastics in the oceans are unknown ${ }^{2}$. With some studies suggesting a persistence of hundreds of years ${ }^{3}$ or fragmentation rates of only $1-5 \%$ per year ${ }^{4}$, this has led us to look towards microbes for a solution to this problem. When plastics enter the environment, they are rapidly covered by organic matter, known as the ecocorona ${ }^{5}$, and are colonised by microbes within minutes ${ }^{6}$. These plastic-colonising microbes - bacteria, fungi and single-celled eukaryotes as well as macro and other organisms - are collectively termed the 'plastisphere' ${ }^{7}$. While marine plastics have long been observed to have a colonising biofilm (e.g., Carpenter \& Smith, $1972{ }^{8}$ ), the first specific characterisation of the plastisphere was published by Zettler et al. in $2013^{7}$, following a call for research into microbial communities on plastics by Harrison et al. in $2011^{9}$. Some earlier studies investigating biofilm formation in the marine environment did also include plastic materials (e.g., ${ }^{10}$ ) or investigated the biomass colonising plastics in relation to plastic degradation (e.g., ${ }^{11}$ ), but the specific focus on the taxonomic or functional characterisation of plastisphere communities has only been within the last approximately eight years. A literature search carried out on $4^{\text {th }}$ January 2021 for the search terms "plastics plastisphere", "plastics microbial community", and "plastics microbial degradation" yielded a total of 1069 unique results. This was supplemented with our own literature collections and filtered manually to include only studies and reviews that fit the following criteria: (i) available online by the beginning of 2021; (ii) examined at least one aspect of the colonisation or degradation of surfaces in the marine environment; and (iii) the surfaces used included at least one recalcitrant, petrochemical plastic. This resulted in 140 primary research articles (Figs. 1 and 2 and Table S1) and 65 review articles (Fig. 3 and Table S2). Remarkably, 34 and 45\% of the research articles and reviews, respectively, published to date were made available online in 2020.

\subsection{Focus of plastisphere studies and methods used}

Each of the 140 plastisphere primary research articles returned by our literature search was reviewed by one of the authors for details relating to the study topic, aims, experimental setup and methods used and key findings (Figs. 1 and 2; full details can be found in Table S1). To date, most plastisphere studies specifically focus (i.e., "study topic"; Fig. 1) on the characterisation of the community structure of the colonising organisms ( $n=60$ ), with a total of 46 or 77 studies (all study topics), that use microscopy to visualise these microbial colonisers or sequence at least one microbial community fraction, respectively. The majority of these use amplicon sequencing of marker genes $(n=74)$ to characterise either the prokaryotes $(n=61)$, the eukaryotes $(n=4)$ or both $(n=9)$. Only three studies returned by our literature search use metagenomic sequencing to characterise the plastisphere ${ }^{12-14}$ (a fourth has since been published; Bhagwat et al. ${ }^{15}$ ) and one of these, Yang et al. ${ }^{13}$, re-analyses data from Bryant et al. ${ }^{12}$, meaning that there are currently only three metagenomic datasets. The remaining 80 studies were focussed on: (i) assessing the biodegradation of plastics by either communities or isolates $(n=30)$, with a total of 36 studies including at least one measure of 
biodegradation, for example, weight loss, spectroscopy or microscopy; (ii) antimicrobial resistance (AMR), pathogenesis or harmful algal blooms ( $\mathrm{HAB} ; n=14)$, with a total of 20 studies including one measure of AMR or pathogenicity, for example, polymerase chain reaction (PCR) for virulence or AMR genes; (iii) vertical transport $(n=9)$, with a total of 11 studies including some measure of vertical transport, for example, an assessment of plastic buoyancy before and after colonisation or an examination of plastic aggregation; or (iv) other ( $n=27)$, i.e., they were focussed on another topic, such as assessing plastic concentrations in a given area but also included some information on or characterisation of the plastisphere. As we previously noted ${ }^{16}$, there are relatively very few studies conducted in the Southern Hemisphere $(n=16)$, only five of which use sequencing to characterise plastisphere communities, while there are a relatively large number of studies conducted around Europe $(n=63)$, particularly in the North, Baltic and Mediterranean Seas.

\subsection{Focus of plastisphere reviews and topics covered}

Each of the 65 review articles returned by our literature search was examined by one of the authors for details on the focus of the review as well as the topics included (Fig. 3). Perhaps unsurprisingly, given that the first specific plastisphere characterisation was only published in $2013^{17}$, the first plastisphere-focussed review was published in $2015{ }^{18}$. All reviews published prior to 2015 were focussed on biodegradation ( $n=11$ ) and the degradation of plastics by communities or consortia wasn't discussed in detail until $2017^{19}$. In total, there are 16, 40, 9 and 3 reviews focussed on the plastisphere, plastic biodegradation, ecotoxicology of plastics or plastic-colonising pathogens, respectively. The first ecotoxicology of plastics review that discussed the plastisphere was published in $2017{ }^{5}$, the first pathogen-focussed review was published in $2016^{20}$, and there are now 20 reviews that give an overview of the plastisphere while there are 50 that give an overview of plastic biodegradation. Interestingly, there are some research areas within both plastisphere and biodegradation topics that have received more attention than others. For example, while 15 reviews discuss microbial community assembly on plastics, only 6 discuss either horizontal or vertical transport that may be mediated or affected by the plastisphere and only 8 or 8 reviews discuss colonising pathogens and AMR or the methods used for plastisphere characterisation, respectively. Likewise, for degradation topics, 37 and 38 reviews discuss plastic degradation by isolates and the pathways or enzymes used for plastic degradation, respectively, but only one review discusses the rate at which degradation can occur, while 22, 18 and 11 reviews discuss factors that limit the degradation of plastics, the methods used to assess plastic degradation or plastic degradation by communities or consortia, respectively. There were intermediate numbers of reviews that included sections on the contaminants and additives of plastics $(n=10)$ or plastic toxicity $(n=19)$, while only four reviews discussed the role of plastics or plastic degradation in biogeochemical cycling.

In the following sections, we give an overview of current knowledge on the plastisphere. In some cases, we point the reader towards other reviews that have covered the topics in more detail. We 
summarise microbial community assemblages, the impact of eukaryotes on shaping the plastisphere, plastic biodegradation by marine microbes, microbial pathogens within the plastisphere and the combined effects of plastic pollution and plastisphere interactions on plastic transport and biogeochemical cycling. Finally, we summarise current knowledge, as well as the future directions suggested by the plastisphere reviews included here. 


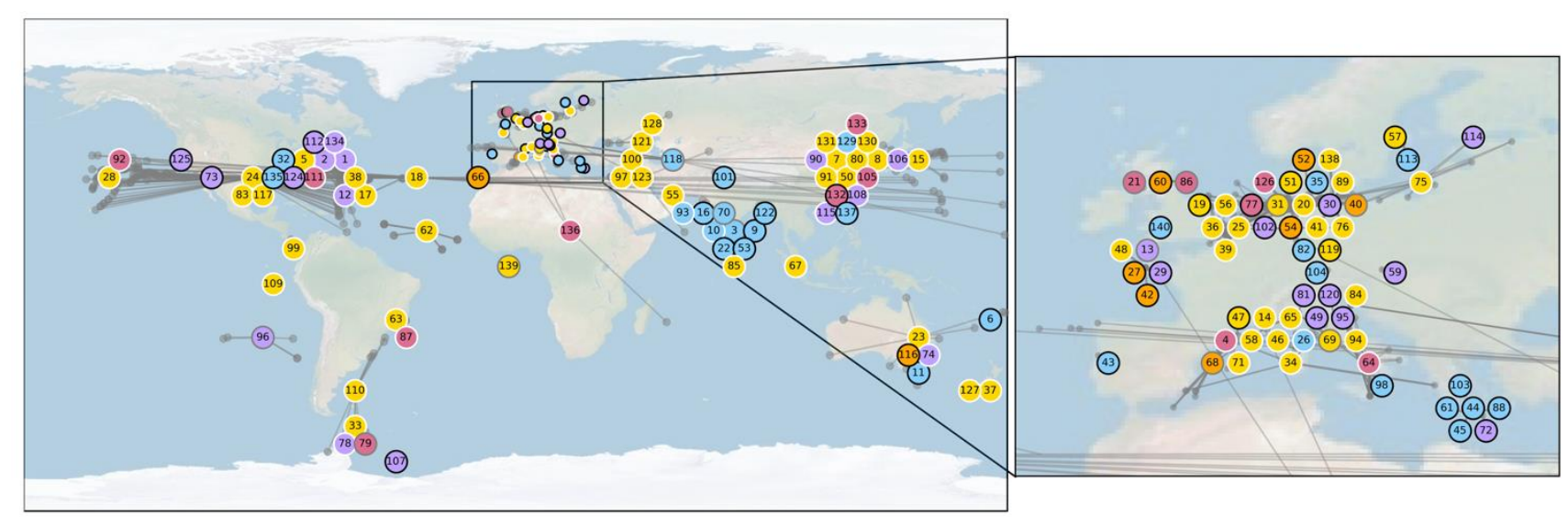

Study topic

Community structure

- Degradation

Vertical transposis \& HAB

- Other

Time points $\begin{aligned} & \text { Collection } \\ & \text { ingle time }\end{aligned}$

AMR, Pathogenesis

Measure include

Measure included
$\square$ Not characterised

Microscopy

Measure included
$\square$ Not characterised
Laboratory/Field

- Laboratory

o Both

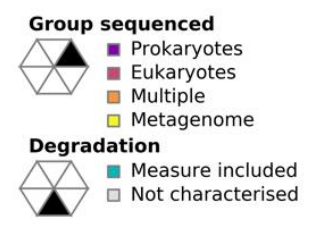

Vertical transport

Measure included

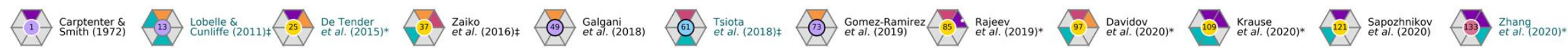
T2- carpenter,

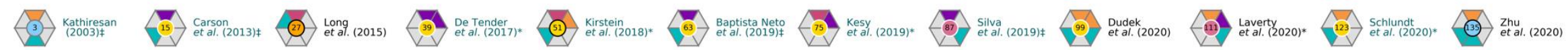

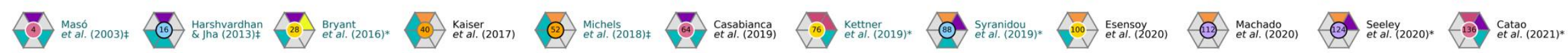

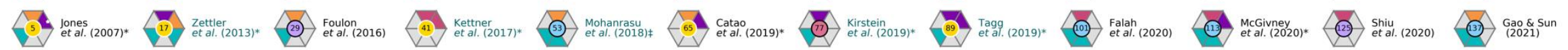

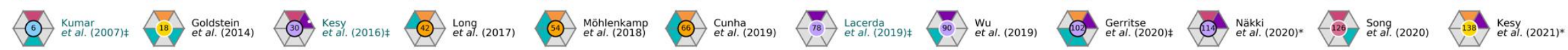

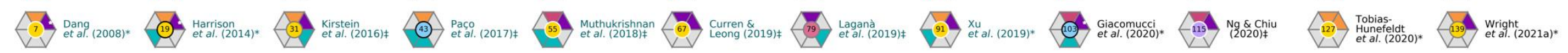

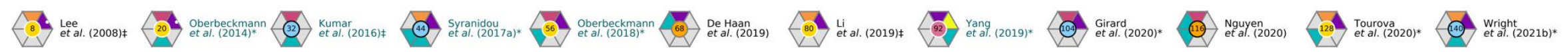

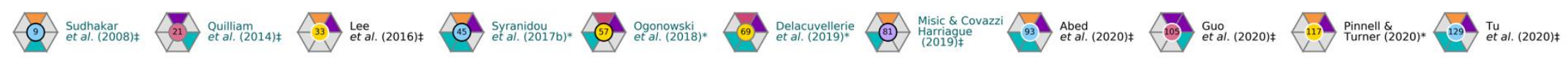

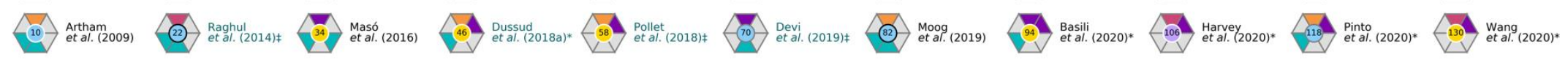
(10) webb.

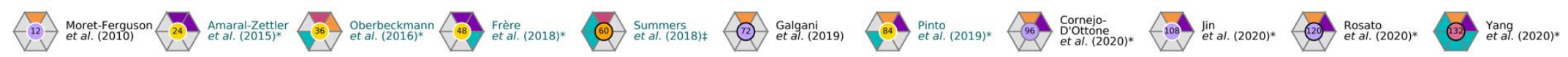

Figure 1. An overview of the sampling locations and methodologies used by all primary research articles that our literature search and subsequent filtering returned ${ }^{4,6-8,10-}$ 
14,16,21-150. All sampling locations are marked by grey points with lines linking them to the numbered study that they were from (top; coloured by the topic that the study is focussed on, with black, white and grey edge colours being for studies carried out in the laboratory, field or both, respectively) with each study being represented by a hexagon (bottom) with six triangles summarising the experimental methodology used (legend top right). Note that white points within the "Group sequenced" triangle indicate that this sequencing was not high throughput, e.g., by Denaturing Gradient Gel Electrophoresis (DGGE) or Terminal Restriction Fragment Length Polymorphism (TRFLP). Study names shown in green were included in our previous review ${ }^{151}$. Asterisks after the study name denote that sequencing data are accessible, while $¥$ denotes that data are not accessible. For example, 132. Yang et al. (2020) ${ }^{56}$ was a laboratory study focussed on AMR, pathogenesis \& HAB that employed a time series for sampling, used amplicon sequencing of the prokaryotes (16S rRNA gene) to characterise the microbial community (and made sequencing data accessible) and included measures of AMR, pathogenesis \& HAB, degradation and microscopy, but did not include any measures of vertical transport. A table with full summaries (an extension of the table included in our previous review ${ }^{151}$ ) of the aims and experimental setup, polymer type, control substrate, community, degradation and aggregation/sinking determination methods and key findings for each study is in Table S1. 


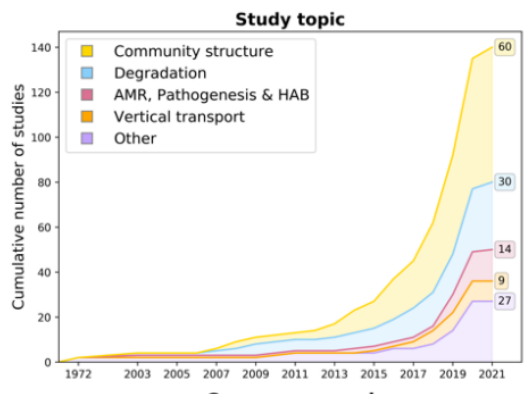

Group sequenced

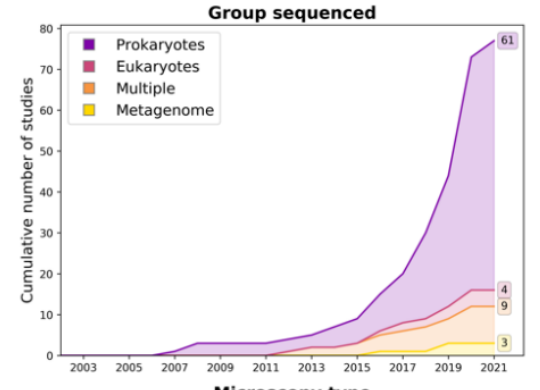

Microscopy type

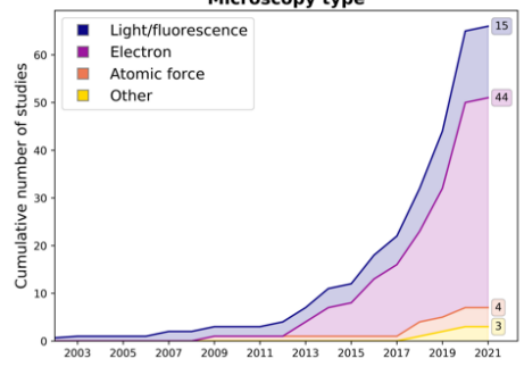

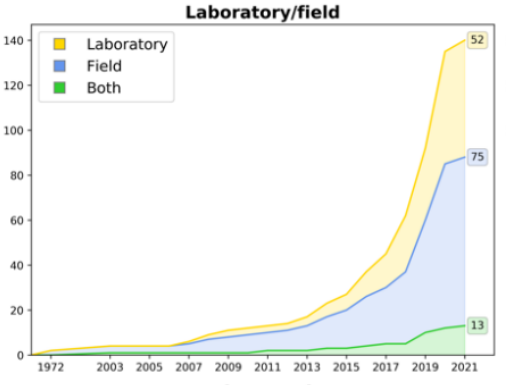

AMR, Pathogenesis \& HAB

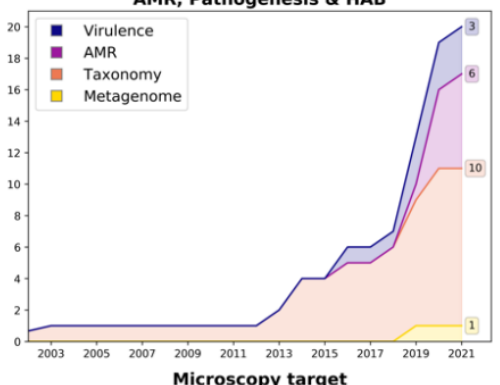

Microscopy target

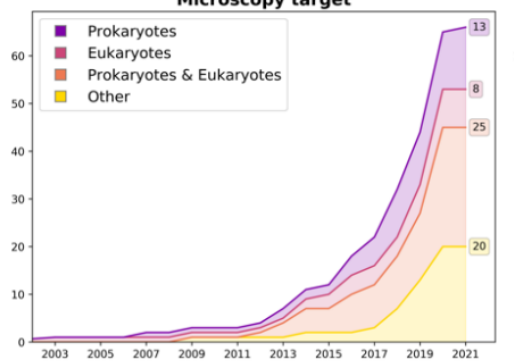

Time points

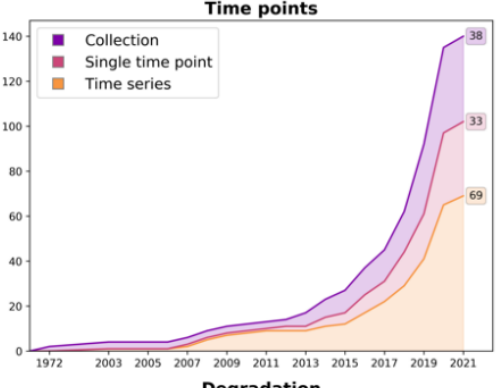

Degradation

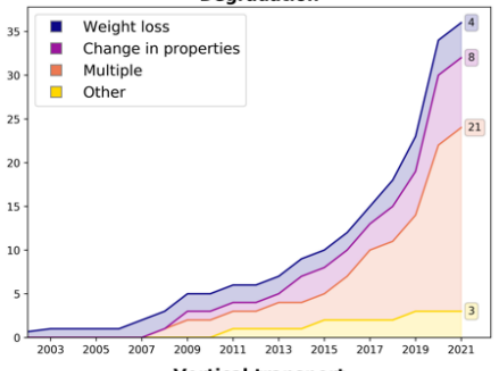

Vertical transport

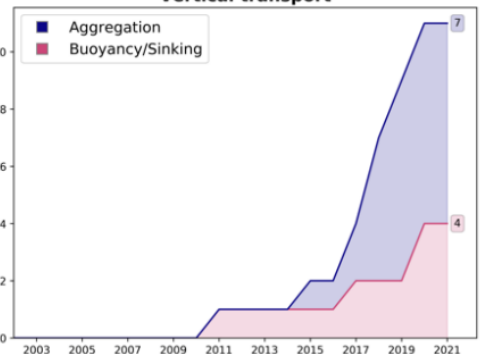

Figure 2. Cumulative number of plastisphere primary research articles published per year relating to different study topics (as in Fig. 1). Note that: (i) $x$ - and $y$-scales vary between panels; (ii) 'AMR' within the AMR, Pathogenesis and HAB panel includes both studies where AMR genes are detected by PCR and studies that have tested susceptibility to antibiotics; (iii) 'Changes in properties' in the Degradation panel includes methods such as Raman or Fourier-Transform Infrared (FTIR) spectroscopy, contact angle measurements (hydrophobicity) and testing for changes in tensile strength or crystallinity; (iv) in the Microscopy type panel, where a study has used multiple types of microscopy, only the method with the highest resolution is listed; and (v) 'Other' in the Microscopy target panel means that the microscopy was not aimed at looking at the colonising taxa (and in most of these cases, biofilms were removed prior to visualisation), and was usually aimed at looking for signs of degradation or fragmentation. 


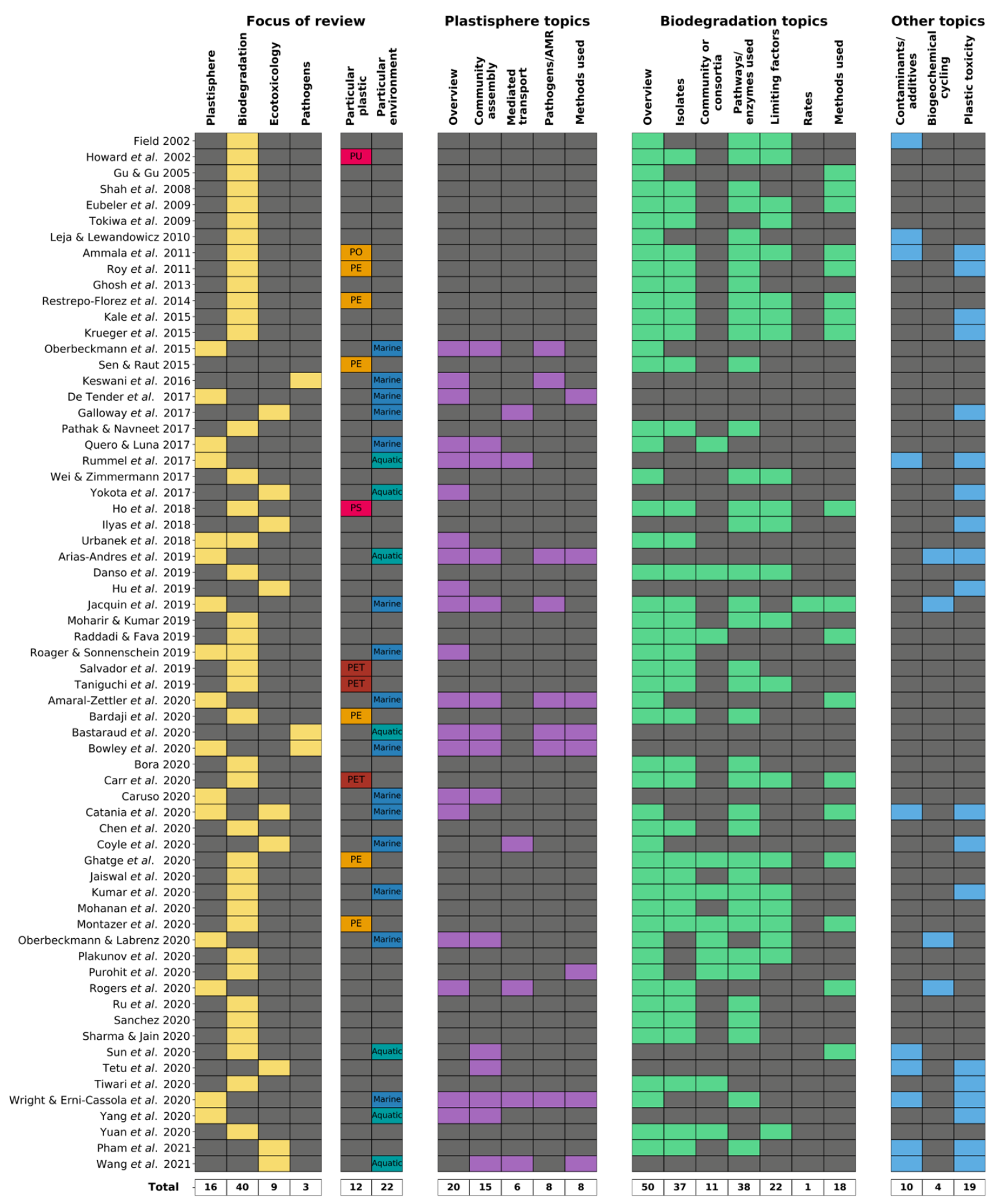

Figure 3. The focus and topics covered of all plastisphere reviews that our literature search and subsequent filtering returned ${ }^{5,18-20,151-211}$. The focus of the review is the over-arching topic that the review addresses, with aquatic referring to both marine and freshwater environments, while plastisphere topics, biodegradation topics and other topics are whether each review has a full, titled section on that theme. Where cells are coloured, these topics are present within the review. Abbreviations are shown where reviews are focussed on a single plastic type: PU (polyurethane), PO (polyolefins), PE (polyethylene), PS (polystyrene) and PET (polyethylene terephthalate). Full details of the topics in each review, as well as the future directions suggested and conclusions drawn by each study are in Table S2. 


\section{The plastisphere as a microbial biofilm on plastics}

The microbial communities on plastics are typically dominated by Proteobacteria ( $70 \%$ relative abundance), Bacteroidetes ( $10 \%)$ and Cyanobacteria ( $20 \%)$. There are usually not large differences in alpha diversity indices between plastics, control marine biofilms and planktonic samples, although some control marine biofilms have been found to have larger proportions of Bacteroidetes ( 20\%) and Planctomycetes ( $5 \%$ ), while planktonic samples have a larger proportion of Verrucomicrobia $(\sim 5 \%)^{16}$. Surprisingly, while our previous review found that just 19 of the 66 studies included a control biofilm surface ${ }^{151}$, there are only an additional 13 studies with a control biofilm surface in the studies evaluated here (i.e., 32 of 140 studies; Table S1). There are a number of factors that influence plastisphere formation and composition - most of which would apply to any aquatic biofilm - which we discuss in this section.

When plastics (or any surface) first enter the environment, they are rapidly covered by organic material and contaminants - the ecocorona ${ }^{5}$ - which facilitates microbial colonisation by reducing the hydrophobicity of the surface ${ }^{151}$. These microbial communities are initially composed of fastgrowing organisms that are good at colonising surfaces. If the surface is degradable, then these first colonisers are gradually replaced by organisms capable of degrading the surface, which will eventually be replaced by cheaters or cross-feeders - organisms that are not capable of degrading the surface but are able to use the sub-products of degradation ${ }^{212}$. Our current understanding of these successional states on plastics is complicated by the long-time scales favoured by many plastics studies (in our recent meta-analysis, the mean incubation time for all samples was 100 days ${ }^{16}$ ). A relatively low proportion of studies to date include characterisation of the eukaryotic or other non-bacterial plastisphere constituents, and we therefore focus on prokaryotes here and discuss eukaryotes separately in the following section. While in our previous review (Wright and Erni-Cassola et al. ${ }^{151}$ ) we reported that only 21 out of 66 studies reviewed included a time series - only 6 of which also sequenced part of the microbial community ${ }^{151}$ - there are now 69 studies (of 140) that include a time series, 32 of which also sequence part of the microbial community (Figs. 1 and 2).

Whilst results fluctuate depending on the individual study, when looking at coarse time scales, current research suggests that the Alphaproteobacteria are generally more abundant at early (below one week) than late (above one week) time points, while the opposite is true for the Gammaproteobacteria, Bacteroidetes and Actinobacteria ${ }^{16}$. However, only 15 of the time series studies include these early time points, with only two studies including sequencing of the microbial community before one day of incubation, Lee et al. (2008) and Kesy et al. (2021) 32,61. Interestingly, Lee et al. ${ }^{32}$ found that, at the earliest time points ( 3 or $9 \mathrm{~h}$ incubation), the Gammaproteobacteria dominate, while their results from 24 or $36 \mathrm{~h}$ of incubation were consistent with that suggested above where the Alphaproteobacteria dominate. The other study including time points of less than one day, Kesy et al. ${ }^{61}$, only reported on the Vibrio genus (Gammaproteobacteria), and while they did find 
colonisation by Vibrio spp. by $1 \mathrm{~h}$ of incubation, further studies (or re-analysis of the data obtained by Kesy et al.) are needed to confirm the findings of Lee et al. in different settings.

The composition of macro-molecules likely drives colonisation in the first few minutes of incubation 213-216, but - as for other substrates - much of the variation in plastisphere composition is driven by stochasticity ${ }^{217}$ as well as environmental variables ${ }^{16,178,194}$. Studies examining which factors have the largest influence on plastisphere composition find that environmental variables such as light availability, salinity and geographical region as well as experimental variables such as DNA extraction method or primer pair used for sequencing have the largest impact on plastisphere composition $16,105,135,194$. Plastic type has also been found to have an impact on plastisphere composition, and some of the discriminating taxa between different plastic types have been suggested to play a role in plastic degradation ${ }^{16,128,135}$, although the extent to which this may occur needs further verification (see below for discussion on this). A preference for a surface-attached rather than planktonic lifestyle is likely also a larger driver of plastisphere composition than plastic type and while many studies have simply compared the plastisphere with the free-living planktonic community (Table S1; $n=23$ ), some studies also include controls of either an inert surface (such as glass, ceramic or shells; $n=28$ ) or particleassociated seawater or sediment communities ( $n=19$; Table S1).

Our knowledge of the functional potential as well as the functional capacity of the plastisphere is currently very limited, although the abilities of plastisphere isolates have been more comprehensively tested. There are just three metagenomic datasets available ${ }^{12,14,15}$ as well as several studies that measure one or several aspects of plastisphere function (discussed further below), e.g., alkane degradation ${ }^{93,94,111}$, antimicrobial resistance ${ }^{26,33,49,56,130,218}$ or pathogenesis ${ }^{80,114,138}$. The metagenomic datasets, collected by Bryant et al. ${ }^{12}$, Pinnell and Turner ${ }^{14}$ and Bhagwat et al. ${ }^{15}$, were from plastics collected from the Northern Pacific Gyre, incubated in coastal Gulf of Mexico sediments or incubated in an Australian estuary, respectively. While Pinnell and Turner and Bhagwat et al. included both control biofilm samples (either ceramic or wood, respectively) and a biodegradable polyester (either polyhydroxyalkanoate $[\mathrm{PHA}]$ or polycaprolactone $[\mathrm{PCL}]$, respectively), Bryant et al. compared the plastisphere only with planktonic samples. It is likely for this reason that while Bryant et al. found that functions including nitrogen fixation, chemotaxis, type IV and VI secretion systems and xenobiotics degradation were significantly enriched on plastics (polyethylene [PE] and polypropylene [PP]), Pinnell and Turner found that recalcitrant plastic biofilms (polyethylene terephthalate [PET]) were not distinguishable from control biofilms (ceramic; although biodegradable plastic biofilms were) and Bhagwat et al. did not find significant functional differences between any material types (PCL, PP, polystyrene [PS], polyvinyl chloride [PVC] and wood). It is therefore important that we continue to design experiments that test whether the functional capacity of plastic biofilms differs from that of other biofilms rather than planktonic samples. 


\section{Importance of eukaryotes in shaping the Plastisphere}

Despite almost 10 years of Plastisphere research, the eukaryotic community fraction has consistently received far less scientific attention compared with prokaryotes (Figs. 1 and 2; 151,178,219). Among the studies included in our literature review, 77 papers characterised plastisphere communities using PCRbased methods, and only 16 of these included a eukaryotic fraction. The highest number of publications per year, so far, was reached for both the prokaryotic and the eukaryotic fractions in 2020. Surprisingly, while there were 29 studies that included the prokaryotes published during 2020 (up from 14 published in 2019), there were only four that included the eukaryotic fraction, although this was still an increase on the three studies published in 2019 (two of which were metagenomes that did not comment on the eukaryotes). Similarly, the representation of eukaryotes in review papers has been modest: we did not include eukaryotes as a category in Figure 3 because none of the review papers in Table S2 contained sections that matched with our inclusion criteria (i.e., section heading with one of the keywords: eukaryote, diatom, dinoflagellate, microalgae, protist). Three degradation themed reviews in total, however, did have at least one section dedicated to fungi $160,193,199$. Furthermore, out of the 65 publications included on our list of plastisphere reviews (Table S2) only one was focussed on eukaryotes, reviewing the potential of fungi to degrade petrochemical plastics 199. The low inclusion rate of eukaryotes in plastisphere research, however, does not correlate with their prevalence or ecological importance in these biofilms: metagenomic investigations in the North Pacific Gyre revealed that $40-99 \%$ of reads from each of the 12 samples analysed were identified as eukaryotic sequences ${ }^{12}$. Due to the highly variable rRNA gene copy number in eukaryotes ${ }^{178,220}$ the number of reads usually does not directly correspond to the number of actual individuals ${ }^{178}$, however, these findings still highlight the significant contribution of eukaryotes to the overall community composition of the plastisphere ${ }^{178}$.

Most plastisphere metabarcoding studies have targeted the overall eukaryotic fraction using the $18 \mathrm{~S}$

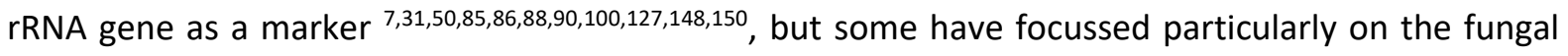
plastisphere fraction ${ }^{31,90}$, in some cases employing fungal-specific ITS ${ }^{148}$ or ITS2 ${ }^{31,87}$ marker genes. Additional markers for marine microalgae (tufA) and metazoans (COI) have also been included on one occasion ${ }^{148}$. Taxa including (but not limited to) members of the diatoms, dinoflagellates, ciliates, fungi, brown, green and red algae, as well as a range of metazoan taxa are often reported as the dominant eukaryotes in the plastisphere (e.g., 7,12,85,86,88,100,127,148,150; ; see also the review by Rogers et al. ${ }^{197}$ ). Indeed, diatoms are consistently described as an abundant and diverse group of colonisers on plastics, particularly during the early stages of biofilm formation $8,22,67,73,85,148,178$, while macro- and microscopic forms of metazoan taxa (e.g., bryozoans, crustaceans, molluscs, anthozoans, sponges, nematodes and annelids) often also make up a major proportion of the eukaryotic communities ${ }^{12,85,86,100,127}$ likely, at least in part, because of their multicellular nature ${ }^{127,178}$. Apart from PCR-based methods, eukaryotic plastisphere members have been described in several publications using microscopy techniques $22,41,44,67,69,73,76,89,113,131$ (Fig. 2). These techniques, however, are not high throughput and do not usually 
provide sufficient coverage or taxonomic resolution for estimation of the whole microbial community 161. They can, however, be useful for revealing structural and spatial details unattainable via sequencing approaches ${ }^{148,161}$, particularly when used in combination with phylogenetic labelling with fluorescent probes ${ }^{46,161}$.

Eukaryotic micro-organisms play several important roles in community regulation, dynamics and functioning in marine biofilms, ranging from photosynthesis and primary production (e.g., diatoms ${ }^{7}$ ) to predation (e.g., predatory ciliates ${ }^{7,88,127}$ and amoebae ${ }^{150}$ ), parasitism (e.g., parasitic dinoflagellates and fungi ${ }^{127}$ ) and other symbiotic interactions (e.g., ectosymbiotic bacteria on ciliates ${ }^{7,127}$ or coralsymbiont dinoflagellates ${ }^{12}$ ) (see review by Amaral-Zettler et al. ${ }^{178}$ ). Several studies have also reported that certain fungal taxa are able to degrade plastics, however only three of these strains are marine (Zalerion maritimum ${ }^{92}$, Aspergillus tubingensis and A. flavus ${ }^{221}$; reviewed by Rogers et al. ${ }^{197}$ and Sanchez ${ }^{199}$ ). Nevertheless, the search for marine plastic degraders has prompted a special interest in fungi and, in recent years, the fungal fraction of the plastisphere - which has been found to comprise approximately $2.8-3 \%$ of the overall eukaryote sequences in field and lab incubations in Baltic (along an estuarine continuum) and North Sea waters, respectively ${ }^{90,100}$ - has been specifically targeted by at least four studies $31,87,90,148$.

Perhaps the most interesting aspect about eukaryotes in the plastisphere, however, is their potential to shape the composition of the prokaryotic community inhabiting the biofilm through eukaryoteprokaryote interactions and close associations ${ }^{12,46,85,127,150}$, some of which are known to be speciesspecific $^{222,223}$. Bacteria can benefit from phytoplankton by gaining access to their cell exudates that provide a source of carbon, energy and nutrients $46,127,224,225$, as well as oxygen produced via photosynthesis (reviewed by Stocker and Seymour ${ }^{226}$ ). Bacteria are often observed either colonising (see review by Amin et al. ${ }^{225}$ ) or living in close proximity ${ }^{46,227}$ to phytoplankton cells, where they may end up as a result of random encounters or active chemotaxis towards the variety of chemical cues originating from the micro-environment surrounding individual phytoplankton cells - the 'phycosphere' (reviewed by Stocker and Seymour and Seymour et al. 226,228). Similar associations, particularly between diatoms and bacteria, have been observed in biofilms on plastics incubated in coastal waters of the Atlantic Ocean and Wadden Sea via microscopy ${ }^{46}$, but also by inference from sequencing data from samples incubated in the North Sea ${ }^{85}$. A co-occurrence network analysis conducted on samples incubated at five locations along a river-Baltic Sea continuum in North-East Germany further suggested that prokaryotic community dynamics on plastic substrates (PE and PS) were largely driven by interactions with the eukaryotic community fraction. Wood substrates, on the other hand, were mainly characterised by connections between bacteria ${ }^{127}$, probably because bacteria were able to use the wood as a carbon source ${ }^{50}$ while inert plastics often support carbonproducing phototrophic communities ${ }^{12,50}$. In addition to plastic surfaces and diatoms, prokaryotes can also attach to and interact with a variety of other eukaryotic organisms ${ }^{12}$, such as encrusting 
bryozoans ${ }^{12,46}$ or ciliates ${ }^{7}$. Interestingly, diatom-associated bacterial groups have often been found dominating bacterial communities on marine biofilms, including those on plastics ${ }^{16,46,85}$.

Dudek et al. ${ }^{150}$ reported that in their time series investigations in the Caribbean Sea, eukaryotes diatoms in particular - were observed to exhibit substrate specificity between the different plastic types incubated, in contrast to prokaryotes. This observation was supported by earlier findings by Eich et al. ${ }^{76}$ where diatom communities differed between PE and a starch-based biodegradable plastic. Phytoplankton are known to produce hydrocarbon compounds, both aliphatic and aromatic, and/or adsorb them from the surrounding seawater, thereby accumulating these compounds in the phycosphere ${ }^{224}$. The potential ramifications of these hydrocarbons for degradation assessments are discussed further below, but further investigations are needed that experimentally address the dynamics of eukaryote-prokaryote interactions in the plastisphere and differentiate them from microbe-plastic interactions (see Bryant et al. ${ }^{12}$ ). Schlundt et al. ${ }^{46}$ recently conducted the first study that incorporates analysis of the spatial structure and eukaryote-prokaryote interactions in the plastisphere by combining phylogenetic labelling (Combinatorial Labelling And Spectral Imaging Fluorescence In Situ Hybridization [CLASI-FISH]) with confocal microscopy, as recommended earlier by Oberbeckmann et al. ${ }^{85}$. We hope that more studies like this will follow in the future, ideally in combination with high-throughput sequencing of all community fractions, elucidating the real drivers behind plastisphere community composition.

\section{Plastic degradation}

Biodegradation refers to the breakdown of organic chemicals by the action of living organisms (i.e., biotic degradation), usually carried out through enzymatic catalysis ${ }^{229}$. However, this process in nature is never isolated from the action of abiotic factors. Hence, biodegradation can be understood as a chemical breakdown of organic molecules by the synergetic contribution of biotic and abiotic factors ${ }^{230}$. There are several key stages in the biodegradation of polymeric hydrocarbons: (i) biodeterioration - a decline in physicochemical properties mediated by microbial activity on the surface of the polymer ${ }^{230}$; (ii) biofragmentation - a lytic process reducing polymer molecular weight ${ }^{230}$; (iii) assimilation - integration of atoms resulting from the fragmentation process into biomass ${ }^{230}$, in this case carbon uptake; and (iv) mineralisation - the process of carbon uptake and complete transformation into biomass, $\mathrm{CO}_{2} / \mathrm{H}_{2} \mathrm{O}$ in oxic environments and $\mathrm{CO}_{2} / \mathrm{CH}_{4} / \mathrm{H}_{2} \mathrm{O}$ in anoxic environments ${ }^{151,210}$. While assimilation and mineralisation are the most significant biological factors, abiotic factors also play a role in biodegradation. The abiotic degradation of polymers produces weathered materials by the action of either temperature, light, gases, mechanical forces, water or a combination of these factors ${ }^{231}$. Depending on the type of weathering, polymers' modifications can take place through different routes. For instance, sunlight can influence the weathering of polymers by the action of ultraviolet (UV) (i.e., photooxidation; UV-A 295-315 nm and UV-B 315-400 nm) radiation and by heating (i.e., thermooxidation) which is mediated by the visible section of sunlight $(400-760 \mathrm{~nm})$ and 
infrared radiation (760-2500 nm) ${ }^{210}$. The oxidation of polymers can be observed by the formation of different chemical groups, such as ketones, carboxylic acid, and esters ${ }^{232}$. The biological degradation of chemicals is an intricate process in which the abiotic contribution is essential as the initial step of the degradation of many recalcitrant polymers ${ }^{233}$, which we focus on here.

Physicochemical properties inherent to the polymers impact the (bio)degradability of a specific material ${ }^{234}$. Among these properties, molecular weight, glass transition temperature, hydrophilic/hydrophobic behaviour and crystallinity are relevant features to look at when determining biodegradability ${ }^{152,234}$. For instance, highly crystalline polymers have shown to be resistant to biodegradation compared with polymers with more amorphous regions - irregular polymer structures that are more susceptible to microbial/enzymatic attack ${ }^{157,235}$. Furthermore, the chemical structure of the polymer itself can indicate how prone to degradation a polymer may be. For instance, polyesters such as PET and PCL contain functional ester groups that serve as susceptible points for the catalytic action of enzymes with esterase activity ${ }^{236}$. On the other hand, polymers with no evident functional groups are less susceptible to enzymatic attack (i.e., more recalcitrant polymers); some examples are typical olefins such as PE and PP. Expectedly, for the potential degradation of polyolefins, it seems essential to have abiotic pre-oxidation, introducing weak points for enzymatic attack; functional groups. This oxidation will generate degradation products of lower molecular weight that can be taken up by cells and metabolised (i.e., mineralised), completing the degradation process ${ }^{233,237}$. Overall, biodegradation requires: (i) the presence of microbes able to access, uptake and mineralise the substrate, (ii) appropriate environmental conditions (e.g., temperature, salinity, $\mathrm{pH}$ ) to propitiate microbial development and (iii) the polymer must be susceptible to enzymatic degradation.

Microbes' potential ability to degrade plastics seems to be well distributed across a wide range of taxa. Furthermore, the majority of putative degraders reported in degradation studies were found in soil $(27.8 \%)$, followed by plastic waste dumping sites (9.6\%) and finally compost $(5.3 \%){ }^{238}$. Interestingly, the isolation and characterisation of aquatic plastic degraders are less frequent ${ }^{239}$, which is probably related to the extra challenge that aquatic environments, such as the oceans, represent (e.g., low nutrient concentration and temperature) compared with soil and compost. In soil and compost, high nutrient availability, humidity and temperature are often conditions in which microorganisms thrive, positively impacting any potential biodegradation processes ${ }^{240}$. As previously explained, functional groups within a polymer (e.g., ester carbonyls and ketones) will serve as a target for the enzymatic breakdown of the polymer. In this regard, lipases and esterases have been connected to the degradation of polyesters such as PET, initially in the terrestrial environment ${ }^{170,241}$ but now also in the marine environment (Table $S 3{ }^{62,63}$ ). Conversely to polyester degradation, the identification of enzymes related to the degradation of polyolefins has been more challenging. So far, we do not think there is sufficient evidence to determine whether this is an active process (i.e., polymer break down mediated by enzymes) or only a passive uptake of the released carbon from the 
process of weathering. However, the degradation of plastics has been repeatedly linked to hydrocarbon degradation, particularly alkane degradation, due to their chemical semblance to polyolefins - inert carbon-based backbone chains ${ }^{242,243}$. Thus, several marine studies have targeted alkane degradation genes, especially the alkane monooxygenase alkB (Table S3 ${ }^{93,94,111}$ ).

To date, there is not a unified fashion to determine plastic degradation in the literature ${ }^{244}$. On the contrary, there are different methods to determine degradation, with the most commonly applied being mass loss, spectroscopic profiles (addition and removal of functional groups) and scanning electron microscopy (SEM; Fig. 2 and Table S3; for more related techniques see Chamas et al. ${ }^{245}$ ). Though these techniques on their own are not enough to properly screen for biodegradation, a combination of these can provide a better idea of the potential of putative plastic degraders. Some other more informative but less frequently applied methods involve tracking the incorporation of isotopically labelled carbon - monitoring the integration of ${ }^{13} \mathrm{C}$-labelled carbon into biological structures and monitoring $\mathrm{CO}_{2}$ evolution ${ }^{197}$. Using a combination of methods to evaluate plastic degradation is especially relevant when the degradation rate is minimal or when plastics contain a high concentration of plasticisers (e.g., PVC contains around $30-80 \%$ plasticisers by weight ${ }^{246}$ ).

Even though plasticisers are chemically complex structures, they are degradable molecules with several described degradation pathways ${ }^{247}$. Furthermore, the hydrocarbons produced by phytoplankton (described above) may provide sustenance for hydrocarbon-degrading bacteria when other sources of hydrocarbons are scarce (see Gutierrez $2018{ }^{224}$ for further discussion), and it has been suggested that diatoms could attract and concentrate hydrocarbon degraders in the plastisphere 150. It is therefore necessary to rule out any preliminary 'positive' results of biodegradation studies that may be attributed to the potential underlying degradation of plasticisers or phytoplanktonproduced hydrocarbons as additional carbon sources - possibly more readily available for microbes to degrade than the plastics themselves. Performing comprehensive studies that monitor the integration of labelled carbon into biomass and characterise the spatial structure of the plastisphere will allow us to go beyond just noting the presence of taxa of interest and will hopefully shed light on potentially conflicting speculations that higher abundances of hydrocarbonoclastic members could be: (i) degrading the plastics ${ }^{119,121}$; (ii) due to UV-induced leaching of degradation products ${ }^{135}$; or (iii) whether these are in response to phototrophs ${ }^{150}$.

\section{Potential pathogens}

After the description of the plastisphere by Zettler et al. ${ }^{7}$, increasing attention has been directed toward identifying and understanding of the potential role of the microbial community drifting along with plastic material in several environments (e.g., oceans, rivers and wastewater). Apart from describing the microbial community on plastic marine debris, Zettler et al. also noted the presence of a Vibrio OTU (Operational Taxonomic Unit). Although the pathogenicity of this OTU could not be 
determined, this has sparked multiple enquiries surrounding the concept of 'harm' relating to plastics, a concept that can potentially have several derivatives. In this sense, the occurrence of potentially pathogenic taxa on plastics has been extensively reviewed ${ }^{20,57,181}$, and several investigations have reported examples of these microorganisms. These are usually referred to as 'potential' pathogens (Table S4), with findings being especially dominated by microorganisms related to Escherichia coli, Vibrio spp. and occasionally to dinoflagellates such as Alexandrium spp. However, it is essential to highlight that the actual pathogenicity of these microorganisms is not usually assessed, and their classification as pathogens is frequently attributed indirectly by mere taxonomic association (Fig. 2). For instance, Vibrio strains are frequently found on marine plastic debris and are automatically associated with the pathogenic members of the genus ${ }^{248}$. Here we give an overview of the genetic material associated with the pathogenic process and antimicrobial resistance in prokaryotes as well as the potential mode of pathogenicity, or toxicity, for micro-eukaryotes.

To gain insight into the harm posed by potentially pathogenic prokaryotic taxa colonising plastic debris, it is useful to look at the primary examples of potential pathogens such as E. coli and Vibrio spp., both found on these materials ${ }^{138}$. Even though there are many examples of pathogenic $E$. coli and Vibrio spp. associated with human disease ${ }^{248,249}$, not all strains are necessarily pathogenic ${ }^{250-253}$. Thus, it is necessary to have substantial evidence to catalogue a particular strain as a pathogen. In this context, several pathogenic or virulence factors are usually used as markers for pathogenicity. For instance, the encoding of adherence factors, toxins, type III and IV secretion systems, among others, are typically targeted as genetic features encoded by pathogenicity islands ${ }^{254,255}$. Of equal importance, pathogenic microorganisms are defined by the presence of a susceptible host - an organism vulnerable to the infection process. The existence of a susceptible host will enable a pathogen to successfully display different infectious traits, determined by genes associated with pathogenicity (i.e., pathogenic factors), which establish the type and infectious impact on the host - human or not ${ }^{256}$. However, despite the relevance of identifying pathogenicity islands and the set of pathogenic factors encoded by these distinct genomic regions, such characterisation of microbial isolates retrieved from plastic debris or metagenomic analysis targeting these genetic elements are not frequently performed. One example is the investigation carried out by Silva et al. ${ }^{138}$, where it was possible to detect several virulence genes from different $E$. coli and Vibrio spp. isolates obtained from plastic debris. Similarly, Kirstein et al. ${ }^{80}$ also tried to identify virulence-related genes in Vibrio spp. isolates retrieved from marine plastics, but none of their isolates encoded any of the targeted virulence genes (Tables S4 and S5).

As noted above, microorganisms' capacity to produce infectious disease relies on the expression of virulence factors. In this context, the host is compelled to retaliate against the intrusion of potentially harmful microbes. When the natural immune response is insufficient, the application of antibiotics may diminish and terminate the infectious process of virulent microbes. Unfortunately, microbes have 
also evolved several strategies to elude antibiotics' effect, a capacity provided by various antibiotic resistance genes (ARGs). The spread of antibiotic-resistant bacteria is considered a matter of global concern ${ }^{257}$. ARGs in virulent microbes can complicate infections, potentially leading to fatal results; it is estimated that annually in the U.S.A., more than 35,000 people die as a consequence of the more than 2.8 million antibiotic resistant infections ${ }^{258}$. Furthermore, it is expected that antimicrobial resistant diseases could push 24 million people into extreme poverty by 2030 and reach a staggering 10 million deaths per year by $2050{ }^{257}$. Therefore, the elucidation of such resistance genes and the physio-pathological activity of microorganisms carrying ARGs have been extensively studied ${ }^{259,260}$. This also includes several investigations trying to determine the potential for plastics to harbour microbes containing such genetic elements. Some prevalent ARGs on plastics are tetracycline (tet) and sulfonamide (sul) resistance genes, together with macrolide-lincosamide-streptogramin (MLS) and multidrug resistance genes; these last two examples especially have been detected by metagenomic analyses (Table S4). Interestingly, extended-spectrum beta-lactamases (ESBLs) are not frequently identified on plastics despite their widespread global distribution ${ }^{49,261,262}$.

Alongside potentially pathogenic bacteria, plastics have also been reported to host potentially pathogenic or HAB-forming microeukaryotes (see Audrezet et al. $2021{ }^{263}$; Table S4); these taxa include members of toxin-producing dinoflagellates (e.g., the genera Alexandrium 7,114,131,150, Amphidinium ${ }^{150}$, Coolia ${ }^{131}$, Heterocapsa ${ }^{127}$, Ostreopsis ${ }^{114,131}$, Pfiesteria ${ }^{127}$ and Prorocentrum ${ }^{83,150}$ ) and diatoms (Pseudo-nitzschia ${ }^{114}$ ) as well as other protists that comprise potential seagrass (Labyrinthulaceae $\mathrm{sp}(\mathrm{p}) .{ }^{150,264}$ ) and coral (Halofolliculina sp. ${ }^{69}$ ) pathogens. As with the potential pathogenicity of plastic-associated bacteria, the hypothetical threats from these micro-eukaryotic rafters are mostly just noted but are rarely tested in any experimental manner, and the harmfulness of micro-eukaryotes may not always be easily determined by amplicon sequencing or taxonomic approaches alone. For example, the toxin production (or lack thereof) of dinoflagellates from the genus Alexandrium, responsible for causing Paralytic Shellfish Poisoning in humans, varies considerably in both quantity as well as quality between - and even within - species, and can also be affected by a number of factors related to growth cycle phase and environmental conditions (reviewed by Murray et al. ${ }^{265}$ ). Likewise, several ecological and environmental factors are likely to regulate their bloom-forming potential in marine waters ${ }^{265}$. To our knowledge, the only marine plastic related study that took this a step further and quantitatively characterised the toxin-production profiles of harmful dinoflagellates (Alexandrium pacificum) isolated from marine plastic debris was that of Casabianca et al. ${ }^{114}$, who found that all of the 10 dinoflagellate strains produced four or more of the 12 Paralytic Shellfish Toxins tested. They further hypothesised that marine plastic debris could accumulate these toxins and aid their transfer through the food web ${ }^{114}$.

Overall, the analysis of plastic samples collected from different environments reveals that potentially virulent - or harmful - microbes and ARGs are present within the plastisphere (Tables S4 and S5). 
Caution is suggested when analysing and interpreting results because of both the uncertainty in determining whether plastisphere microbes are pathogenic and the issues related to transport and plastic residence times, discussed below. However, more robust evidence is necessary when suggesting the presence of pathogens on plastic debris.

\section{Effects of microbe-plastic interactions on plastic buoyancy and transport}

As discussed in the previous sections, marine plastics serve as vectors for a plethora of rafting organisms, including microbes, such as bacteria and microalgae, as well as macro-colonisers (reviewed by Barnes ${ }^{266}$ and Kiessling et al. ${ }^{267}$ ). While many of the taxa found colonising plastics may already be present in the areas in which the plastics are found, there are concerns about members of the plastisphere related to two key themes: the transport of non-indigenous taxa and the transport of pathogenic or harmful taxa, i.e., horizontal transport ${ }^{20,71,80,137}$. Even though in many cases naturally occurrent substrates (e.g., wood, leaves and rocks) are also able to concentrate high abundances and diversity of potential pathogens $49,138,142$, plastics are light-weight and highly resistant to both biotic and abiotic degradation (as discussed above). This means that - whereas naturally occurring organic materials such as wood, leaves or other biogenic substrates will be eventually degraded ${ }^{268}$ - plastics can be easily transported in the environment, from one ecosystem to another. This can occur via rivers ${ }^{269}$, currents ${ }^{270,271}$ and winds ${ }^{272,273}$ as well as rain ${ }^{274}$, snowfall ${ }^{275}$ and melting sea ice ${ }^{276,277}$ and is often referred to as a dynamic process: stranded plastic particles - potentially colonised by resident microbiota - can be subsequently washed back into the water flow and transported downstream or back out to sea. This extended life afloat enables plastic debris to be transported across long distances 278-280, sometimes crossing oceans between continents ${ }^{281,282}$, reaching remote islands ${ }^{266,283}$ and other locations that may host vulnerable ecosystems (e.g., $\left.{ }^{284-286}\right)$.

Several non-indigenous taxa have been documented in association with marine plastic debris (as recently reviewed by Audrezet et al. ${ }^{263}$ ), prompting concerns regarding the ecological impacts caused by the spread of potentially invasive species to new areas (e.g., $\left.{ }^{284-286}\right)$. Caution regarding these potentially harmful rafters seems justified, especially as global warming may further support the spread of non-indigenous or harmful species to new areas, particularly in polar regions ${ }^{27,266}$. Moreover, recent research indicates that ecologically and economically important seagrass meadows 287-291 and other habitat-forming taxa, such as hard corals ${ }^{290}$, can trap and accumulate microplastics, while potential seagrass ${ }^{150}$ and coral ${ }^{69}$ pathogens have been found on plastics and plastic debris has been associated with an increased likelihood of disease on coral reefs ${ }^{292}$. Other taxa that are not generally regarded as invasive, toxic or pathogenic as such, but that can cause nuisance via mucilage events, such as the diatom species Ceratoneis closterium ${ }^{83}$ have also been reported as plastisphere members. Alongside the potential toxicity of the plastic polymer itself, or plastic additives and sorbed contaminants (as reviewed recently by Pham et al. ${ }^{207}$ ), plastics' potential to be considered harmful clearly also depends on the interaction with pathogens and non-native taxa present in the 
environment (see above), especially in polluted environments such as wastewater effluents and water bodies in the proximity of densely populated urbanised areas ${ }^{180}$.

The role of biofouling has long been acknowledged as a factor affecting the buoyancy and potential sedimentation of marine plastics, i.e., vertical transport. Observations of low-density plastics resting on the seafloor or buried in sediments have been reported since the mid-1970's ${ }^{293-295}$. Despite that most plastic debris found in the marine environment are less dense than seawater ${ }^{295,296}$, recently these should-be-buoyant polymers have also been collected from the deeper layers of the water column 297-301, demonstrating the 'fallout' of plastics from surface waters ${ }^{301}$. Due to the rapid colonisation of marine plastics - including by calcareous animals and various types of algae that can cover the plastics with thick, filamentous growth ${ }^{89,266,302,303}$ - the overall density of biofouled particles may exceed that of seawater, causing them to lose buoyancy and sink, as observed in field investigations ${ }^{89,302,303}$. Both experimental field studies and mathematical sinking models have found that biofouled plastics that sink to deeper layers of the water column can also undergo rapid defouling due to a number of factors ${ }^{151,302}$. This could potentially cause them to continue oscillating up and down in the water column as a result of recurring fouling and de-fouling events, thereby retaining the highest microplastic concentrations at mid-depths of the water body ${ }^{304}$ (see Wright and ErniCassola et al. ${ }^{151}$ for further discussion of this topic).

Among the relatively few field-based incubation studies ${ }^{89,302,303}$ and other observations on the topic ${ }^{293}$, buoyancy-loss and biofouling-induced sinking of plastics $(\geq 1 \mathrm{~mm}$ ) in the marine environment have been mainly associated with colonisation by macro-organisms, including calcareous mussels, barnacles and bryozoans ${ }^{89,302,303}$. It is therefore currently unclear whether natural microbial biofouling alone can cause individual, low-density microplastics to sink ${ }^{89,151,303,305}$. While some studies ${ }^{89}$ have concluded that macro-organisms are likely necessary for the transport of buoyant plastics through the water column, others have noted that some macro-organisms (e.g., barnacles) are unlikely to colonise sub-millimetre particles ${ }^{306,307}$. Assuming this statement can be extended to most macro-colonisers, the potential for vertical transport of individual sub-millimetre microplastic particles should depend mainly on microbial colonisation ${ }^{89,151,303}$, although the incorporation of inorganic matter and detritus are likely to play a role as well ${ }^{89,103,308}$. A recent modelling study concluded that small (radius range 10 $\mu \mathrm{m}-1 \mathrm{~mm}$ ) spherical microplastics did not sink within 90 days in oligotrophic ocean waters, where algal growth is scarce ${ }^{65}$. To our knowledge, however, no studies have been published that experimentally investigated the effect of microbial biofouling on the buoyancy of individual, submillimetre low-density microplastics in either lab or field settings, likely due to the difficulties in the handling, recovery and analysis of small particles while retaining natural exposure conditions, as noted by several studies $50,52,89,305,309$. 
The effects of interactions between biogenic material (such as marine snow ${ }^{310}$ and marine microalgae $77,91,103,116$ ) and very small, sub-millimetre microplastics (down to $2 \mu \mathrm{m}$ ) have in fact been investigated in a number of laboratory studies. These studies, however, have either focussed on heteroaggregation $38,77,91,103,116$, rather than the colonisation of individual microplastic particles or polymers that are denser than seawater ${ }^{38}$ (and would therefore readily sink in the marine environment even without biofouling). These studies have found that heteroaggregation can either increase or decrease the settling or rising velocity of microplastics or even change the direction of their movement altogether (i.e., making buoyant polymers sink and non-buoyant polymers float/rise), depending on the polymer type and the composition of the heteroaggregates ${ }^{38,77,91,103,116}$. Biofilm coating has further been shown to promote aggregation between microplastics and natural particles ${ }^{101}$, while field-collected marine aggregates have also been found to incorporate microplastics ${ }^{118,311}$. Despite a number of studies having been published on the sinking and rising behaviour of microplastics incorporated into heteroaggregates, the experimental data needed to enable comparisons between empirical data and mathematical model (e.g. ${ }^{38,151,304,312-314}$ ) predictions is lacking ${ }^{151,314,315}$, specifically: (i) on the effects of microbial biofouling on the buoyancy of individual sub-millimetre microplastics; and (ii) on natural marine biofilm parameters, namely biofilm thickness and density ${ }^{151}$. Further impacts of microbial colonisation on the vertical transport of plastics are related to the ingestion of plastics by macroorganisms ${ }^{5,316,317}$, although micro-eukaryotes, including marine dinoflagellates ${ }^{91}$ and ciliates ${ }^{318}$, have also been observed to ingest small microplastics, possibly making microplastics more bioavailable for marine organisms at higher trophic levels ${ }^{318}$.

\section{Effects of plastic pollution on biogeochemical cycling in the oceans}

Despite being included in the call for research by Harrison et al. (2011) ${ }^{9} 10$ years ago, the potential impacts of plastic pollution and microbe-plastic interactions on ecologically critical biogeochemical processes have remained less discussed (Fig. 3) and largely understudied. This topic is beginning to gain more attention, with a number of studies published so far in 2021, including original research articles (e.g., ${ }^{319,320}$ ) as well as reviews and other works that either focused solely on biogeochemical effects of marine microbe-plastic interactions ${ }^{321}$ or included it as one of several topics (e.g., $219,322,323)$.

Although often referred to as 'inert' materials, plastics can release many chemical compounds ${ }^{321,324}$. This happens when immersed in seawater - particularly when exposed to solar irradiation - and the compounds range from additives ${ }^{325,326}$, metals ${ }^{324,326}$, greenhouse gases (e.g., methane and ethylene ${ }^{327}$ ) and other degradation and weathering products ${ }^{237}$ to pollutants adsorbed from the surrounding environment ${ }^{328}$. Depending on the integrity and chemical composition of the plastic, these leachates can either stimulate ${ }^{59,108}$ or inhibit (e.g., ${ }^{59,324,329}$ ) microbial activity. It has been estimated that dissolved organic carbon (DOC) leaching from marine plastics (i.e., plastic leachates) can amount to up to 23,600 metric tons per year and, in areas with high levels of plastic pollution, could comprise as much as $10 \%$ of all DOC present in the marine surface microlayer ${ }^{108}$. Note that the term DOC is used 
by Romera-Castillo et al. ${ }^{108}$ to include all potential leachates from plastics and has previously been defined as the organic carbon present in water after filtering out particles of approximately $>0.45 \mu \mathrm{m}$ in size ${ }^{330}$. This definition is rather problematic given that nanoplastics $\left(1-1000 \mathrm{~nm}^{331}\right)$ could therefore be included within this and we therefore suggest that future research looks to make a distinction between the 'dissolved' organic carbon that is particulate and that which is in suspension. Nevertheless, this organic carbon is also available for microbial utilisation, enhancing the growth of heterotrophic marine microbes 59,108 . Since marine microbes play a crucial role in global biogeochemical processes, including carbon and nutrient cycling as well as oxygen production and climate regulation, while also forming the basis of marine food webs via primary production ${ }^{332}$, the potential threat of plastic pollution disturbing these processes is not trivial.

The presence of microplastics has been shown to alter the composition of the overall pool of marine Dissolved Organic Matter (DOM) by accumulating light-absorbing and more recalcitrant forms of DOM (i.e., Chromophoric DOM [CDOM]) as a result of increased microbial processes ${ }^{98,321}$. This accumulation of CDOM in surface waters, along with the potential shading effect due to the accumulation of buoyant plastics ${ }^{309}$, could hamper light availability in deeper layers of the water column and have implications for phototrophic primary production as well as the overall marine carbon dynamics ${ }^{98}$. Microplastics can also stimulate microbial production of organic carbon and marine gel particles ${ }^{123}$ which, alongside the demonstrated capacity of microplastics to agglomerate with and alter the sinking rates of natural marine aggregates $38,77,91,103,110,116$ (as discussed above), may potentially affect the functioning of the marine biological pump ${ }^{123,321}$. Several studies have previously suggested that similar effects would be caused by any inert or inorganic particles ${ }^{98,123,333}$, and this hypothesis was recently confirmed ${ }^{320}$. Boldrini et al. ${ }^{320}$ compared the effects of PS microplastics to those of silica gel particles and found that the silica gel particles actually increased the production and transformation of CDOM by microbes even more than microplastics. Indeed, it has long been known that solid particles immersed in seawater adsorb and concentrate nutrients as well as organic matter on their surfaces, transforming them into 'hotspots' ${ }^{12,98,123,309}$ of microbial activity ${ }^{7,334,335}$. This phenomenon has been shown to apply to plastics as well, demonstrated for example by higher bacterial activity on different polymer substrates (i.e., $\mathrm{PE}, \mathrm{PE}$ with pro-oxidant [OXO], thermally aged OXO [AA-OXO] and PHBV) compared with seawater ${ }^{96}$ and by the ability of bacterial communities to remain viable over several months in cultures amended with PET particles, while similar cultures without PET soon died out ${ }^{54,335}$. Plastics, however, compared with other marine particles, pose a greater risk to marine ecosystems because they are a durable and mostly (at least initially ${ }^{321}$ ) buoyant anthropogenic pollutant. Furthermore, their abundance in the environment is only predicted to increase ${ }^{1}$, thereby having the potential to considerably and irreversibly ${ }^{336,337}$ increase the amount of particles affecting microbial activities in the (otherwise largely oligotrophic) oceans ${ }^{12,98,105}$.

In addition to carbon cycling, some studies have demonstrated that microplastics can interfere with nitrogen cycling in marine sediments ${ }^{47,338}$. PVC microplastics were found to inhibit nitrification and 
denitrification in coastal salt marsh sediments in a microcosm study, while microparticles of polyurethane foam (PUF), polylactic acid (PLA) and PE enhanced these processes, although the effect of PE was not statistically significant ${ }^{47}$. Contrastingly, PE microbeads extracted from a cosmetic product were found to impair microbial ammonium removal via denitrification in intertidal sediment microcosms, leading to the accumulation of ammonium in the overlying water which could result in eutrophication and harmful algal bloom incidents in the natural environment ${ }^{338}$. It was suggested that residues of antimicrobial compounds in the cosmetic PE microbeads may have adversely affected the microbial communities responsible for ammonium removal ${ }^{47,338}$, whereas the disruptions to nitrogen cycling in the PVC treatment were possibly caused by sulfide producing bacteria, whose significant enrichment in the PVC treatment was potentially linked to an unidentified additive, highlighting the importance of the chemical composition and additive content of plastics ${ }^{47}$.

Marine plastics harbour microbial communities that are taxonomically ${ }^{7,16}$ and functionally (e.g., enrichment of genes coding for nitrogen fixation ${ }^{12}$; see also a freshwater study ${ }^{309}$ ) distinct from planktonic communities, and conservative estimates reveal that marine plastic biofilms comprise approximately $1 \%$ of the total biomass in the surface microlayer of the oceans ${ }^{58}$. As discussed above, it is unclear whether marine microbes biodegrade and utilise the recalcitrant polymer backbones for growth, although evidence for microbial mineralisation and assimilation of some plastics exists ${ }^{62,63}$. Concerns have, however, been raised regarding the ecological and biogeochemical impact of alterations to the overall marine microbiome as plastic surfaces provide new niches for and enrich taxa that would otherwise be scarce in abundance in the planktonic community fraction ${ }^{12,58,105,194}$. Further, high concentrations of plastic debris are accumulating in oligotrophic open ocean gyres ${ }^{339-}$ 343 , with unknown consequences to the functioning of these ecosystems ${ }^{105,335}$. Increased (heterotrophic) microbial activity is often coupled with increased oxygen consumption ${ }^{309,344}$, which could potentially lead to oxygen depleted conditions in areas with high levels of plastic pollution, including the seafloor (e.g., $30,270,309,345,346$ ). Moreover, the impacts of plastic pollution to primary production by microbial photoautotrophs in the marine environment need further clarifying as floating plastic debris has been described as hotspots for net autotrophic production ${ }^{12}$, while adverse effects on these organisms have also been reported ${ }^{165,324,329,347,348}$. The plastisphere has also been found to contribute to greenhouse gas $\left(\mathrm{CO}_{2}\right.$ and $\left.\mathrm{N}_{2} \mathrm{O}\right)$ fluxes in the eastern South Pacific Ocean, albeit the contribution was rather small (less than $1 \%$ of the overall ocean contribution ${ }^{147}$ ). Experimental evidence also indicates that exposure to plastics and related leachates can negatively affect biocalcification by marine forams, resulting in possible impacts on oceanic carbon storage and consequently climate regulation ${ }^{319}$.

\section{Conclusions and future directions}

We now have a wealth of information on the taxonomic composition of the prokaryotic (particularly bacterial) component of the plastisphere, and whilst we are not advocating for studies to stop 
characterising the prokaryotes, several other areas need further investigation. We have therefore brought together some of the key themes that came up in the conclusions and future directions suggested by many of the reviews returned by our literature search (Fig. 3), namely that future studies should:

(i) use multi-OMIC and interdisciplinary approaches to understand the role of the plastisphere in plastic biodegradation as well as in determining the mechanisms and pathways used for biodegradation 19,151,157,161,164,170,172,175,178,180,181,183,184,188,189,191,194,196,198200,204-207;

(ii) examine the impacts of plastic waste in concert with other ecological threats, such as climate change and antibiotic resistance ${ }^{5,169,181,184}$;

(iii) assess the consequences of the microbial communities on plastics on plastic toxicity and interactions with other organisms and their environments $5,18,151,163,169,180,181,197$;

(iv) empirically investigate the ability of the potentially harmful microbes (including bacteria and micro-eukaryotes) already identified on plastics to induce infection or cause harm 151,172,180,181;

(v) use isotopically labelled plastics or other methods in order to more comprehensively and more easily confirm plastic degradation ${ }^{177,188,193}$ alongside assessments of plastic degradation in the environment $18,19,155,157,172,174,206$.

There are also suggestions by several studies to standardise methodologies in order to increase the ability to draw fair comparisons between different locations and environmental conditions $161,170,171,183,193,197,208,210$. Whilst we agree that standard methodologies or test substrates could be useful tools in order to compare the plastisphere on a global scale and could be incorporated with data collected for the Earth Microbiome Project ${ }^{175,349,350}$, this must be balanced against the rapid development of new and better methodologies, alongside the fact that there are few universally agreed upon best practice methods for microbiome ${ }^{351}$ or plastics research ${ }^{161}$. Furthermore, a standardised methodology is only useful if the authors of studies guarantee that their data is made available upon publication of their study. Even in 2020, $24 \%$ of published plastisphere studies that used next generation sequencing did not make their data accessible (Fig. 1). We therefore urge authors and reviewers to confirm that these data are made accessible at the time of publication, ensuring that these data may be used for other purposes, such as in other meta-analyses ${ }^{16}$, the construction of databases containing known genes for plastic degradation ${ }^{238,352}$, or for the mining of metagenomes for plastic degradation genes ${ }^{353}$.

As discussed above, we are also currently lacking information on the non-bacterial plastisphere constituents; to our knowledge, there are currently no studies reporting on or investigating viruses in the plastisphere, and we have relatively little information on the eukaryotic plastisphere fraction (Fig. 2). We hope that with the decreasing cost and therefore increasing availability of metagenomic 
sequencing, this approach will be used more extensively, and future studies will therefore include information on all taxonomic groups. This will hopefully help to elucidate the role of eukaryotes in shaping the plastisphere. It is currently not clear whether it is 'cost efficient' for hydrocarbonoclastic taxa to degrade plastic polymers (if theoretically capable) when more accessible forms of hydrocarbons may be available from other biofilm members (e.g., diatoms) ${ }^{12,127}$. Therefore, future research should aim to determine whether prokaryotic community composition differs if eukaryotes are excluded from the colonisation process ${ }^{12}$. There are further key research questions brought about by both: (a) the criticisms within the microplastic research field that many studies use unrealistically high particle concentrations (e.g., ${ }^{354-357}$ ), while current levels of larger microplastics $(>10 \mu \mathrm{m})$ are predicted to inflict little ecological harm on the marine environment from an ecotoxicological perspective ${ }^{358,359}$; and (b) the increasing number of studies examining the effects of plastics on biogeochemical cycling (discussed in the previous section). Specifically:

(1) are current concentrations of plastics in the marine environment high enough to induce alterations to biogeochemical processes (either locally or globally)?

(2) if not at the moment, will the situation change in the future if plastic pollution continues to increase as predicted ${ }^{1}$ ?

(3) is there a critical threshold ${ }^{336}$ ?

(4) similar to point (ii) above, will any impacts be amplified by combined effects caused by other environmental stressors, such as global warming or ocean acidification $27,286,319,321$ ?

One suggested solution to the problems caused by the environmental accumulation of traditional (i.e., petrochemical) recalcitrant plastics is the use of biodegradable plastic types (e.g., polylactic acid [PLA], polybutylene adipate terephthalate [PBAT], polybutylene succinate [PBS], PHA and PCL ${ }^{360}$ ). However, the risks and benefits of such replacement must be carefully weighed in light of microbial processes and biogeochemical cycling ${ }^{14,360}$, particularly as high concentrations of bioplastics also have the potential to affect marine carbon, nitrogen and sulphur cycles ${ }^{14,47}$. Together with further implications to marine methanogenesis and cycling of natural PHAs ${ }^{14}$, it seems that replacing traditional plastics with biodegradable ones could lead to an equally bad - or even worse - situation. Therefore, the most important ways of mitigating the effects of plastic pollution are to radically decrease the production and use of single-use plastics - degradable or not - and improve waste management practices globally. 


\section{Supplemental materials}

All supplementary tables are on Figshare: doi.org/10.6084/m9.figshare.14096912

Table S1: Summary of all primary research articles reviewed. Includes references ${ }^{4,6-8,10-14,16,21-150}$.

Table S2: Summary of all plastisphere review articles reviewed. Includes references ${ }^{5,18-20,151-211 .}$

Table S3: The methods used and degradation found by studies including a measurement of

biodegradation. Includes references 4,11,21,23,24,30,35,43,45,52,56,59,62,63,65,68,70,72,76,81,84,92-94,102,104,111,119$122,134,139,144,149,361$

Table S4: Potential pathogens (prokaryotic and eukaryotic) found on plastics by the studies reviewed here. Includes references 7,13,26,33,49,56,57,60,69,71,80,83,97,114,127,130,131,137,138,150,362.

Table S5: Antibiotic resistance genes found on plastics in aquatic environments. Including references $13,26,142,218,362-365$. 


\section{References}

1. Borrelle, S. B. et al. Predicted growth in plastic waste exceeds efforts to mitigate plastic pollution. Science (80-. ). 369, 1515-1518 (2020).

2. Ward, C. P. \& Reddy, C. M. Opinion: We need better data about the environmental persistence of plastic goods. Proc. Natl. Acad. Sci. 117, 202008009 (2020).

3. Avio, C. G., Gorbi, S. \& Regoli, F. Plastics and microplastics in the oceans: From emerging pollutants to emerged threat. Mar. Environ. Res. 128, 2-11 (2016).

4. Gerritse, J., Leslie, H. A., de Tender, C. A., Devriese, L. I. \& Vethaak, A. D. Fragmentation of plastic objects in a laboratory seawater microcosm. Sci. Rep. 10, 1-16 (2020).

5. Galloway, T. S., Cole, M. \& Lewis, C. Interactions of microplastic debris throughout the marine ecosystem. Nat. Ecol. Evol. 1, 1-8 (2017).

6. Harrison, J. P., Schratzberger, M., Sapp, M. \& Osborn, A. M. Rapid bacterial colonization of lowdensity polyethylene microplastics in coastal sediment microcosms. BMC Microbiol. 14, 1-15 (2014).

7. Zettler, E. R., Mincer, T. J. \& Amaral-Zettler, L. A. Life in the 'plastisphere': Microbial communities on plastic marine debris. Environ. Sci. Technol. 47, 7137-7146 (2013).

8. Carpenter, E. J. \& Smith, K. L. J. Plastics on the Sargasso Sea Surface. Science (80-. ). 175, 12401241 (1972).

9. Harrison, J. P., Sapp, M., Schratzberger, M., Mark Osborn, A. \& Osborn, A. M. Interactions between microorganisms and marine microplastics: A call for research. Mar. Technol. Soc. J. 45, 12-20 (2011).

10. Dang, H., Li, T., Chen, M. \& Huang, G. Cross-ocean distribution of Rhodobacterales bacteria as primary surface colonizers in temperate coastal marine waters. Appl. Environ. Microbiol. 74, 52-60 (2008).

11. Artham, T. et al. Biofouling and stability of synthetic polymers in sea water. Int. Biodeterior. Biodegradation 63, 884-890 (2009).

12. Bryant, J. A. et al. Diversity and activity of communities inhabiting plastic debris in the North Pacific Gyre. mSystems 1, e00024-16 (2016).

13. Yang, $Y$. et al. Plastics in the marine environment are reservoirs for antibiotic and metal resistance genes. Environ. Int. 123, 79-86 (2019).

14. Pinnell, L. J. \& Turner, J. W. Shotgun Metagenomics Reveals the Benthic Microbial Community Response to Plastic and Bioplastic in a Coastal Marine Environment. Front. Microbiol. 10, 1-13 (2019).

15. Bhagwat, G. et al. Exploring the Composition and Functions of Plastic Microbiome Using WholeGenome Sequencing. Environ. Sci. Technol. (2021). doi:10.1021/acs.est.0c07952

16. Wright, R. J., Langille, M. G. I. \& Walker, T. R. Food or just a free ride? A meta-analysis reveals the global diversity of the Plastisphere. ISME J. 15, 789-806 (2021).

17. Zettler, E. R., Mincer, T. J. \& Amaral-Zettler, L. A. Life in the "Plastisphere": Microbial communities on plastic marine debris. Environ. Sci. Technol. 47, 7137-7146 (2013).

18. Oberbeckmann, S., Löder, M. G. J. \& Labrenz, M. Marine microplastic-associated biofilms - A review. Environ. Chem. 12, 551-562 (2015).

19. Quero, G. M. \& Luna, G. M. Surfing and dining on the "plastisphere": Microbial life on plastic marine debris. Adv. Oceanogr. Limnol. 8, 199-207 (2017).

20. Keswani, A., Oliver, D. M., Gutierrez, T. \& Quilliam, R. S. Microbial hitchhikers on marine plastic debris: Human exposure risks at bathing waters and beach environments. Mar. Environ. Res. 118, 10-19 (2016).

21. Kumar, S., Hatha, A. A. M. \& Christi, K. S. Diversity and effectiveness of tropical mangrove soil microflora on the degradation of polythene carry bags. Int. J. Trop. Biol. 55, 777-786 (2007).

22. Esensoy, F. B., Senturk, Y. \& Aytan, U. Microbial biofilm on plastics in the southeastern Black Sea. in Marine Litter in the Black Sea 268-286 (2020).

23. Falah, W. et al. Polyethylene terephthalate degradation by Microalga Chlorella vulgaris along with pretreatment. Mater. Plast. 57, 260-270 (2020).

24. Giacomucci, L., Raddadi, N., Soccio, M., Lotti, N. \& Fava, F. Biodegradation of polyvinyl chloride plastic films by enriched anaerobic marine consortia. Mar. Environ. Res. 158, 104949 (2020).

25. Girard, E. B., Kaliwoda, M., Schmahl, W. W., Wörheide, G. \& Orsi, W. D. Biodegradation of textile waste by marine bacterial communities enhanced by light. Environ. Microbiol. Rep. 12, 406-418 (2020). 
26. Guo, X. pan et al. Antibiotic resistance genes in biofilms on plastic wastes in an estuarine environment. Sci. Total Environ. 745, 140916 (2020).

27. Harvey, B. P. et al. Ocean acidification alters bacterial communities on marine plastic debris. Mar. Pollut. Bull. 161, 111749 (2020).

28. Hoffmann, L., Eggers, S. L., Allhusen, E., Katlein, C. \& Peeken, I. Interactions between the ice algae Fragillariopsis cylindrus and microplastics in sea ice. Environ. Int. 139, (2020).

29. Jin, M. et al. How biofilms affect the uptake and fate of hydrophobic organic compounds (HOCs) in microplastic: Insights from an In situ study of Xiangshan Bay, China. Water Res. 184, 116118 (2020).

30. Krause, S. et al. Persistence of plastic debris and its colonization by bacterial communities after two decades on the abyssal seafloor. Sci. Rep. 10, 1-15 (2020).

31. Lacerda, A. L. d. F., Proietti, M. C., Secchi, E. R. \& Taylor, J. D. Diverse groups of fungi are associated with plastics in the surface waters of the Western South Atlantic and the Antarctic Peninsula. Mol. Ecol. 29, 1903-1918 (2020).

32. Lee, J.-W. W., Nam, J.-H. H., Kim, Y.-H. H., Lee, K.-H. H. \& Lee, D.-H. H. Bacterial communities in the initial stage of marine biofilm formation on artificial surfaces. J. Microbiol. 46, 174-182 (2008).

33. Laverty, A. L., Primpke, S., Lorenz, C., Gerdts, G. \& Dobbs, F. C. Bacterial biofilms colonizing plastics in estuarine waters, with an emphasis on Vibrio spp . and their antibacterial resistance. PLoS One 15, (2020).

34. Machado, M. C., Vimbela, G. V., Silva-Oliveira, T. T., Bose, A. \& Tripathi, A. The response of Synechococcus sp. PCC 7002 to micro-/nano polyethylene particles - Investigation of a key anthropogenic stressor. PLoS One 15, 1-14 (2020).

35. McGivney, E. et al. Rapid Physicochemical Changes in Microplastic Induced by Biofilm Formation. Front. Bioeng. Biotechnol. 8, 1-14 (2020).

36. Näkki, P. et al. Polycyclic aromatic hydrocarbon sorption and bacterial community composition of biodegradable and conventional plastics incubated in coastal sediments. Sci. Total Environ. 755, 143088 (2020).

37. Ng, J. C. Y. \& Chiu, J. M. Y. Changes in biofilm bacterial communities in response to combined effects of hypoxia, ocean acidification and nutrients from aquaculture activity in Three Fathoms Cove. Mar. Pollut. Bull. 156, 111256 (2020).

38. Nguyen, T. H., Tang, F. H. M. M. \& Maggi, F. Sinking of microbial-associated microplastics in natural waters. PLoS One 15, 1-20 (2020).

39. Pinnell, L. J. \& Turner, J. W. Temporal changes in water temperature and salinity drive the formation of a reversible plastic-specific microbial community. FEMS Microbiol. Ecol. 96, 1-10 (2020).

40. Pinto, M. et al. Putative degraders of low-density polyethylene-derived compounds are ubiquitous members of plastic-associated bacterial communities in the marine environment. Environ. Microbiol. 22, 4779-4793 (2020).

41. Ramsperger, A. F. R. M. et al. Structural Diversity in Early-Stage Biofilm Formation on Microplastics Depends on Environmental Medium and Polymer Properties. Water 12, (2020).

42. Rosato, A. et al. Microbial colonization of different microplastic types and biotransformation of sorbed PCBs by a marine anaerobic bacterial community. Sci. Total Environ. 705, 135790 (2020).

43. Sudhakar, M., Doble, M., Murthy, P. S. \& Venkatesan, R. Marine microbe-mediated biodegradation of low- and high-density polyethylenes. Int. Biodeterior. Biodegradation 61, 203-213 (2008).

44. Sapozhnikov, P. V, Snigirova, A. \& Kalinina, O. Microphytes assemblages on the neustoplastics from the North Black Sea Microphytes assemblages on the neustoplastics from the North Black Sea. (2020).

45. Sarkhel, R., Sengupta, S., Das, P. \& Bhowal, A. Comparative biodegradation study of polymer from plastic bottle waste using novel isolated bacteria and fungi from marine source. J. Polym. Res. 27, (2020).

46. Schlundt, C. et al. Spatial structure in the "Plastisphere": Molecular resources for imaging microscopic communities on plastic marine debris. Mol. Ecol. Resour. 20, 1-15 (2020).

47. Seeley, M. E., Song, B., Passie, R. \& Hale, R. C. Microplastics affect sedimentary microbial communities and nitrogen cycling. Nat. Commun. 11, 1-10 (2020).

48. Shiu, R. F. et al. Nano- and microplastics trigger secretion of protein-rich extracellular polymeric 
substances from phytoplankton. Sci. Total Environ. 748, 141469 (2020).

49. Song, J. et al. The Travelling Particles: Investigating microplastics as possible transport vectors for multidrug resistant E . coli in the Weser estuary (Germany). Sci. Total Environ. 720, 137603 (2020).

50. Tobias-Hünefeldt, S. P., Wenley, J., Baltar, F. \& Morales, S. E. Ecological drivers switch from bottom-up to top-down during model microbial community successions. ISME J. (2020). doi:10.1038/s41396-020-00833-6

51. Tourova, T. et al. Biodiversity of microorganisms colonizing the surface of polystyrene samples exposed to different aqueous environments. Sustain. 12, 1-23 (2020).

52. Tu, C. et al. Biofilm formation and its influences on the properties of microplastics as affected by exposure time and depth in the seawater. Sci. Total Environ. 734, (2020).

53. Wang, J., Lu, J., Zhang, Y., Wu, J. \& Luo, Y. Unique Bacterial Community of the Biofilm on Microplastics in Coastal Water. Bull. Environ. Contam. Toxicol. 0-4 (2020). doi:10.1007/s00128020-02875-0

54. Webb, H. K., Crawford, R. J., Sawabe, T. \& Ivanova, E. P. Poly(ethylene terephthalate) polymer surfaces as a substrate for bacterial attachment and biofilm formation. Microbes Environ. 24, 39-42 (2009).

55. Wu, N. et al. Colonization characteristics of bacterial communities on microplastics compared with ambient environments (water and sediment) in Haihe Estuary. Sci. Total Environ. 708, (2020).

56. Yang, K. et al. Temporal Dynamics of Antibiotic Resistome in the Plastisphere during Microbial Colonization. Environ. Sci. Technol. 54, 11322-11332 (2020).

57. Zhang, Y., Lu, J., Wu, J., Wang, J. \& Luo, Y. Potential risks of microplastics combined with superbugs: Enrichment of antibiotic resistant bacteria on the surface of microplastics in mariculture system. Ecotoxicol. Environ. Saf. 187, 109852 (2020).

58. Zhao, S., Zettler, E. R., Amaral-Zettler, L. A. \& Mincer, T. J. Microbial carrying capacity and carbon biomass of plastic marine debris. ISME J. 15, 67-77 (2020).

59. Zhu, L., Zhao, S., Bittar, T. B., Stubbins, A. \& Li, D. Photochemical dissolution of buoyant microplastics to dissolved organic carbon: Rates and microbial impacts. J. Hazard. Mater. 383, 121065 (2020).

60. Catao, E. C. P., Gallois, N., Fay, F., Misson, B. \& Briand, J. F. Metal resistance genes enrichment in marine biofilm communities selected by biocide-containing surfaces in temperate and tropical coastal environments. Environ. Pollut. 268, 115835 (2021).

61. Kesy, K., Labrenz, M., Scales, B. S. \& Kreikemeyer, B. Vibrio Colonization Is Highly Dynamic in Early Microplastic-Associated Biofilms as Well as on Field-Collected Microplastics. Microorganisms 9, (2021).

62. Wright, R. J., Bosch, R., Langille, M. G. I. \& Christie-oleza, J. A. A Multi-OMIC Characterisation of Biodegradation and Microbial Community Succession Within the PET Plastisphere. Microbiome 9, 1-22 (2021).

63. Gao, R. \& Sun, C. A marine bacterial community that degrades poly(ethylene terephthalate) and polyethylene. J. Hazard. Mater. 124187 (2021). doi:10.1016/j.jhazmat.2021.125928

64. Morét-Ferguson, S. et al. The size, mass, and composition of plastic debris in the western North Atlantic Ocean. Mar. Pollut. Bull. 60, 1873-1878 (2010).

65. Lobelle, D. \& Cunliffe, M. Early microbial biofilm formation on marine plastic debris. Mar. Pollut. Bull. 62, 197-200 (2011).

66. Briand, J. F. et al. Pioneer marine biofilms on artificial surfaces including antifouling coatings immersed in two contrasting French Mediterranean coast sites. Biofouling 28, 453-463 (2012).

67. Carson, H. S., Nerheim, M. S., Carroll, K. A. \& Eriksen, M. The plastic-associated microorganisms of the North Pacific Gyre. Mar. Pollut. Bull. 75, 126-132 (2013).

68. Harshvardhan, K. \& Jha, B. Biodegradation of low-density polyethylene by marine bacteria from pelagic waters, Arabian Sea, India. Mar. Pollut. Bull. 77, 100-106 (2013).

69. Goldstein, M. C., Carson, H. S. \& Eriksen, M. Relationship of diversity and habitat area in North Pacific plastic-associated rafting communities. Mar. Biol. 161, 1441-1453 (2014).

70. Oberbeckmann, S., Loeder, M. G. J., Gerdts, G. \& Osborn, A. M. Spatial and seasonal variation in diversity and structure of microbial biofilms on marine plastics in Northern European waters. FEMS Microbiol. Ecol. 90, 478-492 (2014).

71. Quilliam, R. S., Jamieson, J. \& Oliver, D. M. Seaweeds and plastic debris can influence the survival of faecal indicator organisms in beach environments. Mar. Pollut. Bull. 84, 201-207 
(2014).

72. Raghul, S. S., Bhat, S. G., Chandrasekaran, M., Francis, V. \& Thachil, E. T. Biodegradation of polyvinyl alcohol-low linear density polyethylene-blended plastic film by consortium of marine benthic vibrios. Int. J. Environ. Sci. Technol. 11, 1827-1834 (2014).

73. Reisser, J. et al. Millimeter-sized marine plastics: A new pelagic habitat for microorganisms and invertebrates. PLoS One 9, 1-11 (2014).

74. Amaral-Zettler, L. A. et al. The biogeography of the Plastisphere: implications for policy. Front. Ecol. Environ. 13, 541-546 (2015).

75. De Tender, C. A. et al. Bacterial community profiling of plastic litter in the Belgian part of the North Sea. Environ. Sci. Technol. 49, 9629-9638 (2015).

76. Eich, A., Mildenberger, T., Laforsch, C. \& Weber, M. Biofilm and diatom succession on polyethylene (PE) and biodegradable plastic bags in two marine habitats: Early signs of degradation in the pelagic and benthic zone? PLoS One 10, 1-16 (2015).

77. Long, M. et al. Interactions between microplastics and phytoplankton aggregates: Impact on their respective fates. Mar. Chem. 175, 39-46 (2015).

78. Foulon, V. et al. Colonization of Polystyrene Microparticles by Vibrio crassostreae: Light and Electron Microscopic Investigation. Environ. Sci. Technol. 50, 10988-10996 (2016).

79. Kesy, K., Oberbeckmann, S., Müller, F. \& Labrenz, M. Polystyrene influences bacterial assemblages in Arenicola marina-populated aquatic environments in vitro. Environ. Pollut. 219, 219-227 (2016).

80. Kirstein, I. V. et al. Dangerous hitchhikers? Evidence for potentially pathogenic Vibrio spp. on microplastic particles. Mar. Environ. Res. 120, 1-8 (2016).

81. Kumar, M., Xie, A. \& Curley, J. Determining the potential secondary impacts associated with microorganismal biodegradation of microplastics in the marine environment. J. Exp. Second. Sci. 3, 1-11 (2016).

82. Lee, Y. M. et al. Succession of bacterial community structure during the early stage of biofilm development in the Antarctic marine environment. Korean J. Microbiol. 52, 49-58 (2016).

83. Masó, M., Fortuño, J.-M., de Juan, S. \& Demestre, M. Microfouling communities from pelagic and benthic marine plastic debris sampled across Mediterranean coastal waters. Sci. Mar. 80, 117-127 (2016).

84. Nauendorf, A. et al. Microbial colonization and degradation of polyethylene and biodegradable plastic bags in temperate fine-grained organic-rich marine sediments. Mar. Pollut. Bull. 103, 168-178 (2016).

85. Oberbeckmann, S., Osborn, A. M. \& Duhaime, M. B. Microbes on a bottle: Substrate, season and geography influence community composition of microbes colonizing marine plastic debris. PLoS One 11, 1-24 (2016).

86. Zaiko, A. et al. Metabarcoding improves detection of eukaryotes from early biofouling communities: implications for pest monitoring and pathway management. Biofouling 32, 671684 (2016).

87. De Tender, C. A. et al. Temporal Dynamics of Bacterial and Fungal Colonization on Plastic Debris in the North Sea. Environ. Sci. Technol. 51, 7350-7360 (2017).

88. Debroas, D., Mone, A. \& Ter Halle, A. Plastics in the North Atlantic garbage patch: A boatmicrobe for hitchhikers and plastic degraders. Sci. Total Environ. 599-600, 1222-1232 (2017).

89. Kaiser, D., Kowalski, N. \& Waniek, J. J. Effects of biofouling on the sinking behavior of microplastics. Environ. Res. Lett. 12, 124003 (2017).

90. Kettner, M. T., Rojas-Jimenez, K., Oberbeckmann, S., Labrenz, M. \& Grossart, H.-P. Microplastics alter composition of fungal communities in aquatic ecosystems. Environ. Microbiol. 19, 4447-4459 (2017).

91. Long, M. et al. Interactions between polystyrene microplastics and marine phytoplankton lead to species-specific hetero-aggregation. Environ. Pollut. 228, 454-463 (2017).

92. Paço, A. et al. Biodegradation of polyethylene microplastics by the marine fungus Zalerion maritimum. Sci. Total Environ. 586, 10-15 (2017).

93. Syranidou, E. et al. Biodegradation of weathered polystyrene films in seawater microcosms. Sci. Rep. 7, 1-12 (2017).

94. Syranidou, E. et al. Development of tailored indigenous marine consortia for the degradation of naturally weathered polyethylene films. PLoS One 12, 1-21 (2017).

95. Dussud, C. et al. Evidence of niche partitioning among bacteria living on plastics, organic particles and surrounding seawaters. Environ. Pollut. 236, 807-816 (2018). 
96. Dussud, C. et al. Colonization of non-biodegradable and biodegradable plastics by marine microorganisms. Front. Microbiol. 9, 1-13 (2018).

97. Frere, L. et al. Microplastic bacterial communities in the Bay of Brest: Influence of polymer type and size. Environ. Pollut. 242, 614-625 (2018).

98. Galgani, L., Engel, A., Rossi, C., Donati, A. \& Loiselle, S. A. Polystyrene microplastics increase microbial release of marine Chromophoric Dissolved Organic Matter in microcosm experiments. Sci. Rep. 8, 1-11 (2018).

99. Jiang, P., Zhao, S., Zhu, L. \& Li, D. Microplastic-associated bacterial assemblages in the intertidal zone of the Yangtze Estuary. Sci. Total Environ. 624, 48-54 (2018).

100. Kirstein, I. V, Wichels, A., Krohne, G. \& Gerdts, G. Mature biofilm communities on synthetic polymers in seawater - Specific or general? Mar. Environ. Res. 142, 147-154 (2018).

101. Michels, J., Stippkugel, A., Lenz, M., Wirtz, K. \& Engel, A. Rapid aggregation of biofilm-covered microplastics with marine biogenic particles. Proc. R. Soc. B Biol. Sci. 285, 1-9 (2018).

102. Mohanrasu, K. et al. Exploring multi potential uses of marine bacteria; an integrated approach for PHB production, PAHs and polyethylene biodegradation. J. Photochem. Photobiol. B Biol. 185, 55-65 (2018).

103. Möhlenkamp, P., Purser, A. \& Thomsen, L. Plastic microbeads from cosmetic products: An experimental study of their hydrodynamic behaviour, vertical transport and resuspension in phytoplankton and sediment aggregates. Elementa 6, (2018).

104. Muthukrishnan, T., Khaburi, M. Al \& Abed, R. M. M. Fouling microbial communities on plastics compared with wood and steel: Are they substrate- or location-specific? Microb. Ecol. (2018).

105. Oberbeckmann, S., Kreikemeyer, B. \& Labrenz, M. Environmental factors support the formation of specific bacterial assemblages on microplastics. Front. Microbiol. 8, 1-12 (2018).

106. Ogonowski, M. et al. Evidence for selective bacterial community structuring on microplastics. Environ. Microbiol. 20, 2796-2808 (2018).

107. Pollet, T. et al. Prokaryotic community successions and interactions in marine biofilms: the key role of Flavobacteriia. FEMS Microb. Ecol. 94, 1-13 (2018).

108. Romera-Castillo, C., Pinto, M., Langer, T. M., Álvarez-Salgado, X. A. \& Herndl, G. J. Dissolved organic carbon leaching from plastics stimulates microbial activity in the ocean. Nat. Commun. 9, 1-7 (2018).

109. Carpenter, E. J., Anderson, S. J., Harvey, G. R., Miklas, H. P. \& Peck, B. B. Polystyrene Spherules in Coastal Waters. Science (80-. ). 178, 749-750 (1972).

110. Summers, S., Henry, T. \& Gutierrez, T. Agglomeration of nano- and microplastic particles in seawater by autochthonous and de novo-produced sources of exopolymeric substances. Mar. Pollut. Bull. 130, 258-267 (2018).

111. Tsiota, P., Karkanorachaki, K., Syranidou, E., Franchini, M. \& Kalogerakis, N. Microbial degradation of HDPE secondary microplastics: Preliminary results. in Proceedings of the International Conference on Microplastic Pollution in the Mediterranean Sea 181-188 (2018). doi:10.1007/978-3-319-71279-6

112. Woodall, L. C. et al. Deep-sea anthropogenic macrodebris harbours rich and diverse communities of bacteria and archaea. PLoS One 1-11 (2018).

113. Baptista Neto, J. A. et al. Microplastics and attached microorganisms in sediments of the Vitória bay estuarine system in SE Brazil. Ocean Coast. Manag. 169, 247-253 (2019).

114. Casabianca, S. et al. Plastic-associated harmful microalgal assemblages in marine environment. Environ. Pollut. 244, 617-626 (2019).

115. Catao, E. C. P. et al. Shear Stress as a Major Driver of Marine Biofilm Communities in the NW Mediterranean Sea. Front. Microbiol. 10, 1-16 (2019).

116. Cunha, C., Faria, M., Nogueira, N., Ferreira, A. \& Cordeiro, N. Marine vs freshwater microalgae exopolymers as biosolutions to microplastics pollution. Environ. Pollut. 249, 372-380 (2019).

117. Curren, E. \& Leong, S. C. Y. Profiles of bacterial assemblages from microplastics of tropical coastal environments. Sci. Total Environ. 655, 313-320 (2019).

118. de Haan, W. P., Sanchez-Vidal, A. \& Canals, M. Floating microplastics and aggregate formation in the Western Mediterranean Sea. Mar. Pollut. Bull. 140, 523-535 (2019).

119. Delacuvellerie, A., Cyriaque, V., Gobert, S., Benali, S. \& Wattiez, R. The plastisphere in marine ecosystem hosts potential specific microbial degraders including Alcanivorax borkumensis as a key player for the low-density polyethylene degradation. J. Hazard. Mater. 380, 120899 (2019).

120. Kathiresan, K. Polythene and plastics-degrading microbes from the mangrove soil. Rev. Biol. Trop. 51, 629-634 (2003). 
121. Devi, R. S., Ramya, R., Kannan, K., Antony, A. R. \& Kannan, V. R. Investigation of biodegradation potentials of high density polyethylene degrading marine bacteria isolated from the coastal regions of Tamil Nadu , India. Mar. Pollut. Bull. 138, 549-560 (2019).

122. Erni-Cassola, G., Wright, R. J., Gibson, M. I. \& Christie-Oleza, J. A. Early Colonization of Weathered Polyethylene by Distinct Bacteria in Marine Coastal Seawater. Microb. Ecol. 79, 517-526 (2019).

123. Galgani, L. et al. Microplastics increase the marine production of particulate forms of organic matter. Environ. Res. Lett. 14, (2019).

124. Gómez-Ramírez, A. L. et al. Biofilm-forming capacity of two benthic microalgae, Navicula incerta and Navicula sp., on three substrates (Naviculales: Naviculaceae). Rev. Biol. Trop. 1-12 (2019).

125. Johansen, M. P. et al. Biofilm-enhanced adsorption of strong and weak cations onto different microplastic sample types: Use of spectroscopy, microscopy and radiotracer methods. Water Res. 158, 392-400 (2019).

126. Kesy, K., Oberbeckmann, S., Kreikemeyer, B. \& Labrenz, M. Spatial Environmental Heterogeneity Determines Young Biofilm Assemblages on Microplastics in Baltic Sea Mesocosms. Front. Microbiol. 10, 1-18 (2019).

127. Kettner, M. T., Oberbeckmann, S., Labrenz, M. \& Grossart, H. P. The eukaryotic life on microplastics in brackish ecosystems. Front. Microbiol. 10, 538 (2019).

128. Kirstein, I. V., Wichels, A., Gullans, E., Krohne, G. \& Gerdts, G. The plastisphere - Uncovering tightly attached plastic "specific" microorganisms. PLoS One 14, 1-17 (2019).

129. Lacerda, A. L. F. et al. Plastics in sea surface waters around the Antarctic Peninsula. Sci. Rep. 9, 1-12 (2019).

130. Laganà, P. et al. Do plastics serve as a possible vector for the spread of antibiotic resistance? First insights from bacteria associated to a polystyrene piece from King George Island (Antarctica). Int. J. Hyg. Environ. Health 222, 89-100 (2019).

131. Masó, M., Garcés, E., Pagès, F. \& Camp, J. Drifting plastic debris as a potential vector for dispersing Harmful Algal Bloom (HAB) species. Sci. Mar. 67, 107-111 (2003).

132. Li, W. et al. Colonization characteristics of bacterial communities on plastic debris, influenced by environmental factors and polymer types in the Haihe Estuary of Bohai Bay, China. Environ. Sci. Technol. acs.est.9b03659 (2019). doi:10.1021/acs.est.9b03659

133. Misic, C. \& Covazzi Harriague, A. Development of marine biofilm on plastic: ecological features in different seasons, temperatures, and light regimes. Hydrobiologia 835, 129-145 (2019).

134. Moog, D. et al. Using a marine microalga as a chassis for polyethylene terephthalate (PET) degradation. Microb. Cell Fact. 18, 1-15 (2019).

135. Pinto, M. et al. The composition of bacterial communities associated with plastic biofilms differs between different polymers and stages of biofilm succession. PLoS One 14, 1-20 (2019).

136. Rajeev, M., Sushmitha, T. J., Toleti, S. R. \& Pandian, S. K. Culture dependent and independent analysis and appraisal of early stage biofilm-forming bacterial community composition in the Southern coastal seawater of India. Sci. Total Environ. 666, 308-320 (2019).

137. Rodrigues, A., Oliver, D. M., Mccarron, A. \& Quilliam, R. S. Colonisation of plastic pellets (nurdles) by E . coli at public bathing beaches. Mar. Pollut. Bull. 139, 376-380 (2019).

138. Muniz Silva, M. et al. Dispersal of potentially pathogenic bacteria by plastic debris in Guanabara Bay, RJ, Brazil. Mar. Pollut. Bull. 141, 561-568 (2019).

139. Syranidou, E. et al. Biodegradation of mixture of plastic films by tailored marine consortia. J. Hazard. Mater. 375, 33-42 (2019).

140. Tagg, A. S., Oberbeckmann, S., Fischer, D., Kreikemeyer, B. \& Labrenz, M. Paint particles are a distinct and variable substrate for marine bacteria. Mar. Pollut. Bull. 146, 117-124 (2019).

141. Jones, P. R., Cottrell, M. T., Kirchman, D. L. \& Dexter, S. C. Bacterial community structure of biofilms on artificial surfaces in an estuary. Microb. Ecol. 53, 153-162 (2007).

142. Wu, X. et al. Selective enrichment of bacterial pathogens by microplastic biofilm. Water Res. 165, 114979 (2019).

143. Xu, X. et al. Marine microplastic-associated bacterial community succession in response to geography, exposure time, and plastic type in China's coastal seawaters. Mar. Pollut. Bull. 145, 278-286 (2019).

144. Abed, R. M. M. M. et al. Degradability and biofouling of oxo-biodegradable polyethylene in the planktonic and benthic zones of the Arabian Gulf. Mar. Pollut. Bull. 150, 110639 (2020).

145. Basili, M. et al. Major Role of Surrounding Environment in Shaping Biofilm Community 
Composition on Marine Plastic Debris. Front. Mar. Sci. 7, 1-12 (2020).

146. Casabianca, S. et al. Physical interactions between marine phytoplankton and PET plastics in seawater. Chemosphere 238, 124560 (2020).

147. Cornejo-D'Ottone, M., Molina, V., Pavez, J. \& Silva, N. Greenhouse gas cycling by the plastisphere: The sleeper issue of plastic pollution. Chemosphere 246, (2020).

148. Davidov, K. et al. Identification of plastic-associated species in the Mediterranean Sea using DNA metabarcoding with Nanopore MinION. Sci. Rep. 10, 1-11 (2020).

149. Denaro, R. et al. Marine hydrocarbon-degrading bacteria breakdown poly(ethylene terephthalate) (PET). Sci. Total Environ. 749, (2020).

150. Dudek, K. L., Cruz, B. N., Polidoro, B. \& Neuer, S. Microbial colonization of microplastics in the Caribbean Sea. Limnol. Oceanogr. Lett. 5, 5-17 (2020).

151. Wright, R. J., Erni-Cassola, G., Zadjelovic, V., Latva, M. \& Christie-Oleza, J. A. Marine plastic debris - a new surface for microbial colonization. Environ. Sci. Technol. 54, 11657-11672 (2020).

152. Tokiwa, Y., Calabia, B. P., Ugwu, C. U. \& Aiba, S. Biodegradability of plastics. Int. J. Mol. Sci. 10, 3722-3742 (2009).

153. Leja, K. \& Lewandowicz, G. Polymer biodegradation and biodegradable polymers - A review. Polish J. Environ. Stud. 19, 255-266 (2010).

154. Ammala, A. et al. An overview of degradable and biodegradable polyolefins. Progress in Polymer Science (Oxford) 36, (Elsevier Ltd, 2011).

155. Roy, P. K., Hakkarainen, M., Varma, I. K. \& Albertsson, A. C. Degradable polyethylene: Fantasy or reality. Environ. Sci. Technol. 45, 4217-4227 (2011).

156. Ghosh, S. K., Pal, S. \& Ray, S. Study of microbes having potentiality for biodegradation of plastics. Env. Sci Pollut Res 20, 4339-4355 (2013).

157. Restrepo-Flórez, J.-M. M., Bassi, A. \& Thompson, M. R. Microbial degradation and deterioration of polyethylene - A review. Int. Biodeterior. Biodegrad. 88, 83-90 (2014).

158. Kale, S. K., Deshmukh, A. G., Dudhare, M. S. \& Patil, V. B. Microbial degradation of plastic: a review. J Biochem Tech 6, 952-961 (2015).

159. Krueger, M. C., Harms, H. \& Schlosser, D. Prospects for microbiological solutions to environmental pollution with plastics. Appl. Microbiol. Biotechnol. 99, 8857-8874 (2015).

160. Sen, S. K. \& Raut, S. Microbial degradation of low density polyethylene (LDPE): A review. J. Environ. Chem. Eng. 3, 462-473 (2015).

161. De Tender, C. et al. A review of microscopy and comparative molecular-based methods to characterize 'Plastisphere' communities. Anal. Methods 9, 2132-2143 (2017).

162. Pathak, V. M. \& Navneet. Review on the current status of polymer degradation: a microbial approach. Bioresour. Bioprocess. 4, 15 (2017).

163. Rummel, C. D., Jahnke, A., Gorokhova, E., Kühnel, D. \& Schmitt-Jansen, M. Impacts of biofilm formation on the fate and potential effects of microplastic in the aquatic environment. Environ. Sci. Technol. Lett. 4, 258-267 (2017).

164. Wei, R. \& Zimmermann, W. Microbial enzymes for the recycling of recalcitrant petroleumbased plastics: how far are we? Microb. Biotechnol. 10, 1308-1322 (2017).

165. Yokota, K. et al. Finding the missing piece of the aquatic plastic pollution puzzle: Interaction between primary producers and microplastics. Limnol. Oceanogr. Lett. 2, 91-104 (2017).

166. Ho, B. T., Roberts, T. K. \& Lucas, S. An overview on biodegradation of polystyrene and modified polystyrene: the microbial approach. Crit. Rev. Biotechnol. 38, 308-320 (2018).

167. Ilyas, M. et al. Plastic waste as a significant threat to environment - A systematic literature review. Rev. Environ. Health 33, 383-406 (2018).

168. Urbanek, A. K., Rymowicz, W. \& Mirończuk, A. M. Degradation of plastics and plastic-degrading bacteria in cold marine habitats. Appl. Microbiol. Biotechnol. 102, 7669-7678 (2018).

169. Arias-Andres, M., Rojas-Jimenez, K. \& Grossart, H.-P. P. Collateral effects of microplastic pollution on aquatic microorganisms: An ecological perspective. TrAC-Trends Anal. Chem. 112, 234-240 (2019).

170. Danso, D., Chow, J. \& Streita, W. R. Plastics: Environmental and biotechnological perspectives on microbial degradation. Appl. Environ. Microbiol. 85, 1-14 (2019).

171. Hu, D., Shen, M., Zhang, Y., Li, H. \& Zeng, G. Microplastics and nanoplastics: would they affect global biodiversity change? Environ. Sci. Pollut. Res. 26, 19997-20002 (2019).

172. Jacquin, J. et al. Microbial ecotoxicology of marine plastic debris: A review on colonization and biodegradation by the "plastisphere". Front. Microbiol. 10, 1-16 (2019). 
173. Moharir, R. V. \& Kumar, S. Challenges associated with plastic waste disposal and allied microbial routes for its effective degradation: A comprehensive review. J. Clean. Prod. 208, 6576 (2019).

174. Raddadi, N. \& Fava, F. Biodegradation of oil-based plastics in the environment: Existing knowledge and needs of research and innovation. Sci. Total Environ. 679, 148-158 (2019).

175. Roager, L. \& Sonnenschein, E. C. Bacterial Candidates for Colonization and Degradation of Marine Plastic Debris. Environ. Sci. Technol. 53, 11636-11643 (2019).

176. Salvador, M. et al. Microbial genes for a circular and sustainable Bio-PET economy. Genes (Basel). 10, 1-15 (2019).

177. Taniguchi, I. et al. Biodegradation of PET: Current Status and Application Aspects. ACS Catal. 9, 4089-4105 (2019).

178. Amaral-Zettler, L. A., Zettler, E. R. \& Mincer, T. J. Ecology of the plastisphere. Nat. Rev. Microbiol. 18, 139-151 (2020).

179. Bardají, D. K. R., Moretto, J. A. S., Furlan, J. P. R. \& Stehling, E. G. A mini-review: current advances in polyethylene biodegradation. World J. Microbiol. Biotechnol. 36, 1-10 (2020).

180. Bastaraud, A., Cecchi, P., Handschumacher, P., Altmann, M. \& Jambou, R. Urbanization and waterborne pathogen emergence in low-income countries: Where and how to conduct surveys? Int. J. Environ. Res. Public Health 17, 1-19 (2020).

181. Bowley, J., Baker-austin, C., Porter, A., Hartnell, R. \& Lewis, C. Oceanic Hitchhikers - Assessing Pathogen Risks from Marine Microplastic. Trends Microbiol. xx, 1-10 (2020).

182. Bora, D. K. Rise of the sustainable circular economy platform from waste plastics: A biotechnological perspective. MRS Energy Sustain. 7, 1-8 (2020).

183. Carr, C. M., Clarke, D. J. \& Dobson, A. D. W. Microbial Polyethylene Terephthalate Hydrolases: Current and Future Perspectives. Front. Microbiol. 11, 1-23 (2020).

184. Caruso, G. Microbial colonization in marine environments: Overview of current knowledge and emerging research topics. J. Mar. Sci. Eng. 8, 1-22 (2020).

185. Catania, V., Cascio Diliberto, C., Cigna, V. \& Quatrini, P. Microbes and Persistent Organic Pollutants in the Marine Environment. Water. Air. Soil Pollut. 231, (2020).

186. Chen, C. C., Dai, L., Ma, L. \& Guo, R. T. Enzymatic degradation of plant biomass and synthetic polymers. Nat. Rev. Chem. 4, 114-126 (2020).

187. Coyle, R., Hardiman, G. \& Driscoll, K. O. Microplastics in the marine environment: A review of their sources, distribution processes and uptake into ecosystems. Case Stud. Chem. Environ. Eng. 2, 100010 (2020).

188. Ghatge, S., Yang, Y., Ahn, J. H. \& Hur, H. G. Biodegradation of polyethylene: a brief review. Appl. Biol. Chem. 63, (2020).

189. Jaiswal, S., Sharma, B. \& Shukla, P. Integrated approaches in microbial degradation of plastics. Environ. Technol. Innov. 17, 100567 (2020).

190. A., G. K., K., A., M., H., K., S. \& G., D. Review on plastic wastes in marine environment Biodegradation and biotechnological solutions. Mar. Pollut. Bull. 150, 110733 (2020).

191. Mohanan, N., Montazer, Z., Sharma, P. K. \& Levin, D. B. Microbial and Enzymatic Degradation of Synthetic Plastics. Front. Microbiol. 11, (2020).

192. Field, J. A. Limits of anaerobic biodegradation. Water Sci. Technol. 45, 9-18 (2002).

193. Montazer, Z., Najafi, M. B. H. \& Levin, D. B. Challenges with verifying microbial degradation of polyethylene. Polymers (Basel). 12, (2020).

194. Oberbeckmann, S. \& Labrenz, M. Marine Microbial Assemblages on Microplastics: Diversity, Adaptation, and Role in Degradation. Ann. Rev. Mar. Sci. 12, 1-24 (2020).

195. Plakunov, V. K., Gannesen, A. V, Mart, S. V \& Zhurina, M. V. Biocorrosion of Synthetic Plastics : Degradation Mechanisms and Methods of Protection. Microbiology 89, 647-659 (2020).

196. Purohit, J., Chattopadhyay, A. \& Teli, B. Metagenomic Exploration of Plastic Degrading Microbes for Biotechnological Application. Curr. Genomics 21, 253-270 (2020).

197. Rogers, K. L. et al. Micro-by-micro interactions: How microorganisms influence the fate of marine microplastics. Limnol. Oceanogr. Lett. 5, 18-36 (2020).

198. Ru, J., Huo, Y. \& Yang, Y. Microbial Degradation and Valorization of Plastic Wastes. Front. Microbiol. 11, 1-20 (2020).

199. Sánchez, C. Fungal potential for the degradation of petroleum-based polymers: An overview of macro- and microplastics biodegradation. Biotechnol. Adv. 40, 107501 (2020).

200. Sharma, B. \& Jain, P. Deciphering the advances in bioaugmentation of plastic wastes. J. Clean. Prod. 275, 123241 (2020). 
201. Sun, Y. et al. Laboratory simulation of microplastics weathering and its adsorption behaviors in an aqueous environment: A systematic review. Environ. Pollut. 265, 114864 (2020).

202. Tetu, S. G. \& Moore, L. R. How will marine plastic pollution affect bacterial primary producers ? Commun. Biol. 3, 20-23 (2020).

203. Howard, G. T. Biodegradation of polyurethane: A review. Int. Biodeterior. Biodegrad. 49, 245252 (2002).

204. Tiwari, N., Santhiya, D. \& Sharma, J. G. Microbial remediation of micro-nano plastics: Current knowledge and future trends. Environ. Pollut. 265, 115044 (2020).

205. Yang, Y., Liu, W., Zhang, Z., Grossart, H. P. \& Gadd, G. M. Microplastics provide new microbial niches in aquatic environments. Appl. Microbiol. Biotechnol. 104, 6501-6511 (2020).

206. Yuan, J. et al. Microbial degradation and other environmental aspects of microplastics/plastics. Sci. Total Environ. 715, 136968 (2020).

207. Pham, T. H. et al. Global challenges in microplastics: From fundamental understanding to advanced degradations toward sustainable strategies. Chemosphere 267, 129275 (2021).

208. Wang, X. et al. A review of microplastics aggregation in aquatic environment: Influence factors, analytical methods, and environmental implications. J. Hazard. Mater. 402, 123496 (2021).

209. Gu, J. G. \& Gu, J. D. Methods currently used in testing microbiological degradation and deterioration of a wide range of polymeric materials with various degree of degradability: $A$ review. J. Polym. Environ. 13, 65-74 (2005).

210. Shah, A. A., Hasan, F., Hameed, A. \& Ahmed, S. Biological degradation of plastics: A comprehensive review. Biotechnol. Adv. 26, 246-265 (2008).

211. Eubeler, J. P., Zok, S., Bernhard, M. \& Knepper, T. P. Environmental biodegradation of synthetic polymers I. Test methodologies and procedures. TrAC - Trends Anal. Chem. 28, 1057-1072 (2009).

212. Datta, M. S., Sliwerska, E., Gore, J., Polz, M. F. \& Cordero, O. X. Microbial interactions lead to rapid micro-scale successions on model marine particles. Nat. Commun. 7, 1-7 (2016).

213. Siboni, N., Lidor, M., Kramarsky-Winter, E. \& Kushmaro, A. Conditioning film and initial biofilm formation on ceramics tiles in the marine environment. FEMS Microbiol. Lett. 274, $24-29$ (2007).

214. Dang, H. \& Lovell, C. R. Microbial Surface Colonization and Biofilm Development in Marine Environments. Microbiol. Mol. Biol. Rev. 80, 91-138 (2016).

215. Jain, A. \& Bhosle, N. B. Biochemical composition of the marine conditioning film: implications for bacterial adhesion. Biofouling 25, 13-19 (2009).

216. Petrova, O. E. \& Sauer, K. Sticky Situations: Key Components That Control Bacterial Surface Attachment. J. Bacteriol. 2413-2425 (2012). doi:10.1128/JB.00003-12

217. Wright, R. J. R. J., Gibson, M. I. M. I. \& Christie-Oleza, J. A. J. A. Understanding microbial community dynamics to improve optimal microbiome selection. Microbiome 7, 1-14 (2019).

218. Wang, S. et al. Selectively Enrichment of antibiotics and ARGs by microplastics in river, estuary and marine waters. Sci. Total Environ. 134594 (2020). doi:10.1016/j.scitotenv.2019.134594

219. Onda, D. F. L. \& Sharief, K. M. Identification of Microorganisms Related to Microplastics. in Handbook ofMicroplastics in the Environment (2021). doi:10.1007/978-3-030-10618-8

220. Zhu, F., Massana, R., Not, F., Marie, D. \& Vaulot, D. Mapping of picoeucaryotes in marine ecosystems with quantitative PCR of the 18S rRNA gene. FEMS Microbiol. Ecol. 52, 79-92 (2005).

221. Devi, R. S. et al. Biodegradation of HDPE by Aspergillus spp . from marine ecosystem of Gulf of Mannar, India. Mar. Pollut. Bull. 96, 32-40 (2015).

222. Koedooder, C. et al. Diatom-Bacteria Interactions Modulate the Composition and Productivity of Benthic Diatom Biofilms. Front. Microbiol. 10, 1-11 (2019).

223. Jackrel, S. L., Yang, J. W., Schmidt, K. C. \& Denef, V. J. Host specificity of microbiome assembly and its fi tness effects in phytoplankton. ISME J. (2020). doi:10.1038/s41396-020-00812-x

224. Gutierrez, T. Occurrence and Roles of the Obligate Hydrocarbonoclastic Bacteria in the Ocean When There Is No Obvious Hydrocarbon Contamination. in Taxonomy, Genomics and Ecophysiology ofHydrocarbon-Degrading Microbes (ed. McGenity, T.) (Springer, Cham, 2018). doi:10.1007/978-3-030-14796-9

225. Amin, S. A., Parker, M. S. \& Armbrust, E. V. Interactions between Diatoms and Bacteria. Microbiol. Mol. Biol. Rev. 76, 667-684 (2012).

226. Stocker, R. \& Seymour, J. R. Ecology and Physics of Bacterial Chemotaxis in the Ocean. Microbiol. Mol. Biol. Rev. 76, 792-812 (2012). 
227. Thompson, H. F., Summers, S. \& Yuecel, R. Hydrocarbon-Degrading Bacteria Found Tightly Associated with the $50-70 \mu \mathrm{m}$ Cell-Size Population of Eukaryotic Phytoplankton in Surface Waters of a Northeast Atlantic Region. Microorganisms 8, 1-16 (2020).

228. Seymour, J. R., Amin, S. A., Raina, J.-B. \& Stocker, R. Zooming in on the phycosphere: the ecological interface for phytoplankton - bacteria relationships. Nat. Microbiol. 2, (2017).

229. Crawford, R. L. Biodegradation: Principles, Scope, and Technologies. in Comprehensive Biotechnology 1, 3-13 (Elsevier B.V., 2011).

230. Lucas, N. et al. Polymer biodegradation: Mechanisms and estimation techniques. Chemosphere 73, 429-442 (2008).

231. Crawford, C. B. \& Quinn, B. Physiochemical properties and degradation. in Microplastic Pollutants (2017). doi:10.1016/B978-0-12-809406-8.00004-9

232. Gardette, M. et al. Photo- and thermal-oxidation of polyethylene: Comparison of mechanisms and in $\mathrm{fl}$ uence of unsaturation content. Polym. Degrad. Stab. 98, 2383-2390 (2013).

233. Hakkarainen, M. \& Albertsson, A. Environmental Degradation of Polyethylene. Adv Polym Sci 169, 177-199 (2004).

234. Min, K., Cuiffi, J. D. \& Mathers, R. T. Ranking environmental degradation trends of plastic marine debris based on physical properties and molecular structure. Nat. Commun. 11, (2020).

235. Balani, K., Verma, V., Agarwal, A. \& Narayan, R. Physical, thermal, and mechanical properties of polymers. in Biosurfaces: A Materials Science and Engineering Perspective 329-344 (2015).

236. Zheng, Y., Yanful, E. K. \& Bassi, A. S. A Review of Plastic Waste Biodegradation. Crit. Rev. Biotechnol. 25, 243-250 (2005).

237. Gewert, B., Plassmann, M., Sandblom, O. \& Macleod, M. Identification of chain scission products released to water by plastic exposed to ultraviolet light. Environ. Sci. Technol. Lett. 5, 272-276 (2018).

238. Gambarini, V. et al. Phylogenetic Distribution of Plastic-Degrading Microorganisms. mSystems 6, 1-13 (2021).

239. Zrimec, J., Kokina, M., Jonasson, S., Zorrilla, F. \& Zelezniak, A. Plastic-degrading potential across the global microbiome correlates with recent pollution trends. bioRxiv 1-23

240. Haider, T. P., Volker, C., Kramm, J., Landfester, K. \& Wurm, F. R. Plastics of the Future? The Impact of Biodegradable Polymers on the Environment and on Society. Angew. Chemie - Int. Ed. 58, 50-62 (2019).

241. Yoshida, S. et al. A bacterium that degrades and assimilates poly(ethylene terephthalate). Science (80-. ). 351, 1196-1199 (2016).

242. Jeon, H. J. \& Kim, M. N. Functional analysis of alkane hydroxylase system derived from Pseudomonas aeruginosa E7 for low molecular weight polyethylene biodegradation. Int. Biodeterior. Biodegradation 103, 141-146 (2015).

243. Yoon, M. G., Jeon, H. J. \& Kim, M. N. Biodegradation of Polyethylene by a Soil Bacterium and AlkB Cloned Recombinant Cell. J. Bioremediation Biodegrad. 3, (2012).

244. Zumstein, M. T., Narayan, R., Kohler, H.-P. E., McNeill, K. \& Sander, M. Dos and Do Nots When Assessing the Biodegradation of Plastics. Environ. Sci. Technol. 53, 9967-9969 (2019).

245. Chamas, A. et al. Degradation Rates of Plastics in the Environment. ACS Sustain. Chem. Eng. 8, 3494-3511 (2020).

246. Rahman, M. \& Brazel, C. S. The plasticizer market: an assessment of traditional plasticizers and research trends to meet new challenges. Prog. Polym. Sci. 29, 1223-1248 (2004).

247. Wright, R. J., Bosch, R., Gibson, M. I. \& Christie-Oleza, J. A. Plasticizer degradation by marine bacterial isolates: a proteogenomic and metabolomic characterization. Environ. Sci. Technol. 54, 2244-2256 (2020).

248. Baker-Austin, C. et al. Vibrio spp. infections. Nat. Rev. Dis. Prim. 4, 1-19 (2018).

249. Kaper, J. B., Nataro, J. P. \& Mobley, H. L. T. Pathogenic Escherichia coli. Nat. Rev. Microbiol. 2, 123-140 (2004).

250. Taylor, J. A. \& Barrow, G. I. A non-pathogenic vibrio for the routine quality control of TCBS cholera medium. J Clin Pathol 34, 208-212 (1981).

251. Lorenz, B., Ali, N., Bocklitz, T. \& Rösch, P. Discrimination between pathogenic and nonpathogenic E . coli strains by means of Raman microspectroscopy. Anal. Bioanal. Chem. 412, 8241-8247 (2020).

252. Sarowska, J. et al. Virulence factors, prevalence and potential transmission of extraintestinal pathogenic Escherichia coli isolated from different sources : recent reports. Gut Pathog. 1-16 (2019). doi:10.1186/s13099-019-0290-0 
253. Julie, D. et al. Ecology of pathogenic and non-pathogenic Vibrio parahaemolyticus on the French Atlantic coast . Effects of temperature, salinity, turbidity and chlorophyll a. Environ. Microbiol. 12, 929-937 (2010).

254. Hacker, J. \& Kaper, J. B. Pathogenicity islands and the evolution of microbes. Annu Rev Microbiol 54, 641-79 (2000).

255. Schmidt, H. \& Hensel, M. Pathogenicity Islands in Bacterial Pathogenesis. Clin. Microbiol. Rev. 17, 14-56 (2004).

256. Casadevall, A. \& Pirofski, L. What Is a Host? Attributes of Individual Susceptibility. Infect. Immun. 86, 1-12 (2018).

257. World Health Organization. Available at: who.int.

258. Centers for Disease Control and Prevention.

259. Peterson, J. Bacterial Pathogenesis. in Medical Microbiology (ed. Baron, S.) (1996).

260. Foster, T. J. Antibiotic resistance in Staphylococcus aureus. Current status and future prospects. FEMS Microbiol. Rev. 41, 430-449 (2017).

261. Amos, G. C. A., Hawkey, P. M., Gaze, W. H. \& Wellington, E. M. Waste water effluent contributes to the dissemination of CTX-M-15 in the natural environment. J. Antimicrob. Chemother. 69, 1785-1791 (2014).

262. Hawkey, P. M. Multidrug-resistant Gram-negative bacteria. J. Hosp. Infect. 89, 241-7 (2015).

263. Audrézet, F. et al. Biosecurity implications of drifting marine plastic debris: Current knowledge and future research. Mar. Pollut. Bull. 162, (2021).

264. Sullivan, B. K., Sherman, T. D., Damare, V. S., Lilje, O. \& Gleason, F. H. Potential roles of Labyrinthula spp . in global seagrass population declines. Fungal Ecol. 6, 328-338 (2013).

265. Murray, S., John, U., Savela, H. \& Kremp, A. 4 Alexandrium spp.: genetic and ecological factors influencing saxitoxin production and proliferation. Clim. Chang. Mar. Freshw. Toxins 133-166 (2015). doi:10.1515/9783110625738-004

266. Barnes, D. K. A. Invasions by marine life on plastic debris. Nature 416, 808-809 (2002).

267. Kiessling, T., Gutow, L. \& Thiel, M. Marine Litter as Habitat and Dispersal Vector. in Marine Anthropogenic Litter (eds. Bergmann, M., Gutow, L. \& Klages, M.) 141-181 (2015). doi:10.1007/978-3-319-16510-3_6

268. Kooi, M., Besseling, E., Kroeze, C., Wezel, A. P. Van \& Koelmans, A. A. Modeling the Fate and Transport of Plastic Debris in Freshwaters : Review and Guidance. in Freshwater Microplastics 125-152 (2018). doi:10.1007/978-3-319-61615-5

269. Lebreton, L. C. M. et al. River plastic emissions to the world's oceans. Nat. Commun. 8, 1-10 (2017).

270. Kane, I. A. et al. Seafloor microplastic hotspots controlled by deep-sea circulation. Science (80.). 638, 1140-1145 (2020).

271. Zhang, H. Transport of microplastics in coastal seas. Estuar. Coast. Shelf Sci. 199, 74-86 (2017).

272. Allen, S. et al. Atmospheric transport and deposition of microplastics in a remote mountain catchment. Nat. Geosci. 12, 339-344 (2019).

273. Zhang, Y. et al. Atmospheric microplastics: A review on current status and perspectives. EarthScience Rev. 203, 1-15 (2020).

274. Brahney, J., Hallerud, M., Heim, E., Hahnenberger, M. \& Sukumaran, S. Plastic rain in protected areas of the United States. Science (80-. ). 368, 1257-1260 (2020).

275. Bergmann, M. et al. White and wonderful? Microplastics prevail in snow from the Alps to the Arctic. Sci. Adv. 5, 1-11 (2019).

276. Obbard, R. W. et al. Global warming releases microplastic legacy frozen in Arctic Sea ice. Earth's Futur. 315-320 (2014). doi:10.1002/2014EF000240.Abstract

277. Peeken, I. et al. Arctic sea ice is an important temporal sink and means of transport for microplastic. Nat. Commun. 9, (2018).

278. Thiel, M., Gutow, L., Ciencias, F. \& Católica, U. The ecology of rafting in the marine environment. I. The floating substrata. Oceanography and Marine Biology: An Annual Review 42, (2005).

279. Chubarenko, I., Bagaev, A., Zobkov, M. \& Esiukova, E. On some physical and dynamical properties of microplastic particles in marine environment. Mar. Pollut. Bull. 108, 105-112 (2016).

280. Van Sebille, E. et al. The physical oceanography of the transport of floating marine debris. Environ. Res. Lett. 15, (2020).

281. Holmes, A. M., Oliver, P. G., Trewhella, S., Hill, R. \& Quigley, D. T. G. Trans-atlantic rafting of inshore Mollusca on Macro-Litter: American molluscs on British and Irish shores, new records. 
J. Conchol. 42, 41-49 (2015).

282. West, J. A., Hansen, G. I., Hanyuda, T. \& Zuccarello, G. C. Flora of drift plastics: a new red algal genus, Tsunamia transpacifica (Stylonematophyceae) from Japanese tsunami debris in the northeast Pacific. Algae 31, 289-301 (2016).

283. Rech, S., Thiel, M., Borrell Pichs, Y. J. \& García-Vazquez, E. Travelling light: Fouling biota on macroplastics arriving on beaches of remote Rapa Nui (Easter Island) in the South Pacific Subtropical Gyre. Mar. Pollut. Bull. 137, 119-128 (2018).

284. Gregory, M. R. Environmental implications of plastic debris in marine settings- entanglement, ingestion, smothering, hangers-on, hitch-hiking and alien invasions. Philos. Trans. R. Soc. B Biol. Sci. 364, 2013-2025 (2009).

285. Barnes, D. K. A. et al. Marine plastics threaten giant Atlantic Marine Protected Areas. Curr. Biol. 28, R1137-R1138 (2018).

286. Horton, A. A. \& Barnes, D. K. A. Microplastic pollution in a rapidly changing world: Implications for remote and vulnerable marine ecosystems. Sci. Total Environ. 738, 140349 (2020).

287. Jones, K. L., Hartl, M. G. J., Bell, M. C. \& Capper, A. Microplastic accumulation in a Zostera marina L. bed at Deerness Sound, Orkney, Scotland. Mar. Pollut. Bull. 152, 110883 (2020).

288. Huang, Y. et al. New Insights into the Microplastic Enrichment in the Blue Carbon Ecosystem: Evidence from Seagrass Meadows and Mangrove Forests in Coastal South China Sea. Environ. Sci. Technol. (2021). doi:10.1021/acs.est.0c07289

289. Sanchez-Vidal, A., Canals, M., de Haan, W. P., Romero, J. \& Veny, M. Seagrasses provide a novel ecosystem service by trapping marine plastics. Sci. Rep. 11, 1-7 (2021).

290. de Smit, J. C. et al. Habitat-forming species trap microplastics into coastal sediment sinks. Sci. Total Environ. 772, 145520 (2021).

291. Bonanno, G. \& Orlando-bonaca, M. Marine plastics: What risks and policies exist for seagrass ecosystems in the Plasticene? Mar. Pollut. Bull. 158, 111425 (2020).

292. Lamb, J. B. et al. Plastic waste associated with disease on coral reefs. Science (80-. ). 2010, 2629 (2018).

293. Holmström, A. Plastic films on the bottom of the Skagerack. Nature 255, 622-623 (1975).

294. Erni-Cassola, G., Zadjelovic, V., Gibson, M. I. \& Christie-Oleza, J. A. Distribution of plastic polymer types in the marine environment; A meta-analysis. J. Hazard. Mater. 369, 691-698 (2019).

295. Schwarz, A. E., Ligthart, T. N., Boukris, E., van Harmelen, T. \& Harmelen, T. Van. Sources, transport, and accumulation of different types of plastic litter in aquatic environments: $A$ review study. Mar. Pollut. Bull. 143, 92-100 (2019).

296. Geyer, R., Jambeck, J. R. \& Law, K. L. Production, use, and fate of all plastics ever made. Sci. Adv. 3, 19-24 (2017).

297. Song, Y. K. et al. Horizontal and Vertical Distribution of Microplastics in Korean Coastal Waters. Environ. Sci. Technol. 52, 12188-12197 (2018).

298. Pabortsava, K. \& Lampitt, R. S. High concentrations of plastic hidden beneath the surface of the Atlantic Ocean. Nat. Commun. 11, 1-11 (2020).

299. Li, D. et al. Profiling the Vertical Transport of Microplastics in the West Pacific Ocean and the East Indian Ocean with a Novel in Situ Filtration Technique. Environ. Sci. Technol. 54, 1297912988 (2020).

300. Uurasjärvi, E., Pääkkönen, M., Setälä, O., Koistinen, A. \& Lehtiniemi, M. Microplastics accumulate to thin layers in the stratified Baltic Sea. Environ. Pollut. 268, (2021).

301. Egger, M., Sulu-Gambari, F. \& Lebreton, L. First evidence of plastic fallout from the North Pacific Garbage Patch. Sci. Rep. 10, 1-10 (2020).

302. Ye, S. \& Andrady, A. L. Fouling of floating plastic debris under Biscayne Bay exposure conditions. Mar. Pollut. Bull. 22, 608-613 (1991).

303. Fazey, F. M. C. \& Ryan, P. G. Biofouling on buoyant marine plastics: An experimental study into the effect of size on surface longevity. Environ. Pollut. 210, 354-360 (2016).

304. Kooi, M., Van Nes, E. H., Scheffer, M. \& Koelmans, A. A. Ups and Downs in the Ocean: Effects of Biofouling on Vertical Transport of Microplastics. Environ. Sci. Technol. 51, 7963-7971 (2017).

305. Leiser, R. et al. Interaction of cyanobacteria with calcium facilitates the sedimentation of microplastics in a eutrophic reservoir. Water Res. 189, (2021).

306. Fazey, F. M. C. \& Ryan, P. G. Debris size and buoyancy influence the dispersal distance of stranded litter. Mar. Pollut. Bull. (2016). doi:10.1016/j.marpolbul.2016.06.039 
307. Lobelle, D. et al. Global modeled sinking characteristics of biofouled microplastic. J. Geophys. Res. Ocean. 1-15 (2021). doi:10.1029/2020jc017098

308. Wu, N. et al. Co-effects of biofouling and inorganic matters increased the density of environmental microplastics in the sediments of Bohai Bay coast. Sci. Total Environ. 717, (2020).

309. Arias-Andres, M., Klümper, U., Rojas-Jimenez, K. \& Grossart, H.-P. Microplastic pollution increases gene exchange in aquatic ecosystems. Environ. Pollut. 237, 253-261 (2018).

310. Porter, A., Lyons, B. P., Galloway, T. S. \& Lewis, C. N. Role of Marine Snows in Microplastic Fate and Bioavailability. Environ. Sci. Technol. 52, 7111-7119 (2018).

311. Zhao, S., Ward, J. E., Danley, M. \& Mincer, T. J. Field-Based Evidence for Microplastic in Marine Aggregates and Mussels: Implications for Trophic Transfer. Environ. Sci. Technol. 52, 1103811048 (2018).

312. Isachenko, I., Khatmullina, L., Chubarenko, I. \& Stepanova, N. Settling velocity of marine microplastic particles: laboratory tests. Geophys. Res. Abstr. EGU Gen. Assem. 18, 2016-6553 (2016).

313. Van Melkebeke, M., Janssen, C. \& De Meester, S. Characteristics and Sinking Behavior of Typical Microplastics including the Potential Effect of Biofouling: Implications for Remediation. Environ. Sci. Technol. 54, 8668-8680 (2020).

314. Waldschläger, K., Born, M., Cowger, W., Gray, A. \& Schüttrumpf, H. Settling and rising velocities of environmentally weathered micro- and macroplastic particles. Environ. Res. 191, (2020).

315. Kowalski, N., Reichardt, A. M. \& Waniek, J. J. Sinking rates of microplastics and potential implications of their alteration by physical, biological, and chemical factors. Mar. Pollut. Bull. 109, 310-319 (2016).

316. Botterell, Z. L. R. et al. Bioavailability of Microplastics to Marine Zooplankton: Effect of Shape and Infochemicals. Environ. Sci. Technol. 54, 12024-12033 (2020).

317. Cole, M. et al. Microplastics alter the properties and sinking rates of zooplankton faecal pellets. Environ. Sci. Technol. 50, 3239-3246 (2016).

318. Zhang, Y., Wang, J., Geng, X. \& Jiang, Y. Does microplastic ingestion dramatically decrease the biomass of protozoa grazers? A case study on the marine ciliate Uronema marinum. Chemosphere 267, 129308 (2021).

319. Birarda, G. et al. Plastics, (bio)polymers and their apparent biogeochemical cycle: An infrared spectroscopy study on foraminifera. Environ. Pollut. 279, 116912 (2021).

320. Boldrini, A., Galgani, L., Consumi, M. \& Loiselle, S. A. Microplastics Contamination versus Inorganic Particles: Effects on the Dynamics of Marine Dissolved Organic Matter. Environments 8, 21 (2021).

321. Galgani, L. \& Loiselle, S. A. Plastic pollution impacts on marine carbon biogeochemistry. Environ. Pollut. 268, 115598 (2021).

322. Wang, J., Peng, C., Li, H., Zhang, P. \& Liu, X. The impact of microplastic-microbe interactions on animal health and biogeochemical cycles: A mini-review. Sci. Total Environ. 773, 145697 (2021).

323. Yan, B. et al. Microplastic Pollution in Marine Environment: Occurrence, Fate, and Effects (With a Specific Focus on Biogeochemical Carbon and Nitrogen Cycles). in Microplastic Pollution (2021).

324. Tetu, S. G. et al. Plastic leachates impair growth and oxygen production in Prochlorococcus, the ocean's most abundant photosynthetic bacteria. Commun. Biol. 2, 1-9 (2019).

325. Hermabessiere, L. et al. Occurrence and effects of plastic additives on marine environments and organisms: A review. Chemosphere 182, 781-793 (2017).

326. Capolupo, M., Sørensen, L., Jayasena, K. D. R., Booth, A. M. \& Fabbri, E. Chemical composition and ecotoxicity of plastic and car tire rubber leachates to aquatic organisms. Water Res. 169, 115270 (2020).

327. Royer, S.-J., Ferron, S., Wilson, S. T. \& Karl, D. M. Production of methane and ethylene from plastic in the environment. PLoS One 13, 1-13 (2018).

328. León, V. M. et al. Potential transfer of organic pollutants from littoral plastics debris to the marine environment. Environ. Pollut. 236, 442-453 (2018).

329. Sarker, I., Moore, L. R., Paulsen, I. T. \& Tetu, S. G. Assessing the Toxicity of Leachates From Weathered Plastics on Photosynthetic Marine Bacteria Prochlorococcus. Front. Mar. Sci. 7, 114 (2020).

330. Zsolnay, Á. Dissolved organic matter: Artefacts, definitions, and functions. Geoderma 113, 187209 (2003). 
331. Hartmann, N. B. et al. Are We Speaking the Same Language? Recommendations for a Definition and Categorization Framework for Plastic Debris. Environ. Sci. Technol. 53, 1039-1047 (2019).

332. Cavicchioli, R. et al. Scientists' warning to humanity: microorganisms and climate change. Nat. Rev. Microbiol. 17, 569-586 (2019).

333. Galgani, L. \& Loiselle, S. A. Plastic accumulation in the sea surface microlayer: An experimentbased perspective for future studies. Geosci. 9, 8-10 (2019).

334. Zobell, C. E. The Effect of Solid Surfaces upon Bacterial Activity1. J. Bacteriol. 46, 39-56 (1943).

335. Mincer, T. J., Zettler, E. R. \& Amaral-Zettler, L. A. Biofilms on Plastic Debris and Their Influence on Marine Nutrient Cycling, Productivity, and Hazardous Chemical Mobility. Handb. Environ. Chem. 78, 221-233 (2016).

336. Villarrubia-Gómez, P., Cornell, S. E. \& Fabres, J. Marine plastic pollution as a planetary boundary threat - The drifting piece in the sustainability puzzle. Mar. Policy 96, 213-220 (2018).

337. Law, K. L. \& Thompson, R. C. Microplastics in the seas. Science (80-. ). 345, 144-145 (2014).

338. Cluzard, M., Kazmiruk, T. N., Kazmiruk, V. D. \& Bendell, L. I. Intertidal Concentrations of Microplastics and Their Influence on Ammonium Cycling as Related to the Shellfish Industry. Arch. Environ. Contam. Toxicol. 69, 310-319 (2015).

339. Kaiser, J. The dirt on Ocean garbage patches. Science (80-. ). 328, 1506 (2010).

340. Van Sebille, E. et al. Origin, dynamics and evolution of ocean garbage patches from observed surface drifters. Environ. Res. Lett. 7, 044040 (2012).

341. Cózar, A. et al. Plastic debris in the open ocean. Proc. Natl. Acad. Sci. 111, 10239-10244 (2014).

342. Lebreton, L. et al. Evidence that the Great Pacific Garbage Patch is rapidly accumulating plastic. Sci. Rep. 8, 1-15 (2018).

343. Egger, M. et al. A spatially variable scarcity of floating microplastics in the eastern North Pacific Ocean. Environ. Res. Lett. 15, (2020).

344. Jonas, R. B. Bacteria, Dissolved Organics and Oxygen Consumption in Salinity Stratified Chesapeake Bay, an Anoxia Paradigm. Am. Zool. 37, 612-620 (1997).

345. Woodall, L. C. et al. The deep sea is a major sink for microplastic debris. R. Soc. Open Sci. 1, (2014).

346. Zalasiewicz, J. et al. The geological cycle of plastics and their use as a stratigraphic indicator of the Anthropocene. Anthropocene 13, 4-17 (2016).

347. Sjollema, S. B., Redondo-Hasselerharm, P., Leslie, H. A., Kraak, M. H. S. \& Vethaak, A. D. Do plastic particles affect microalgal photosynthesis and growth? Aquat. Toxicol. 170, 259-261 (2016).

348. Wang, S. et al. The interactions between microplastic polyvinyl chloride and marine diatoms: Physiological, morphological, and growth effects. Ecotoxicol. Environ. Saf. 203, (2020).

349. Gilbert, J. A., Jansson, J. K. \& Knight, R. The Earth Microbiome project: Successes and aspirations. BMC Biol. 12, 1-4 (2014).

350. Thompson, L. R. et al. A communal catalogue reveals Earth's multiscale microbial diversity. Nature (2017). doi:10.1038/nature24621

351. Knight, R. et al. Best practices for analysing microbiomes. Nat. Rev. Microbiol. 16, 410-422 (2018).

352. Gan, Z. \& Zhang, H. PMBD: a Comprehensive Plastics Microbial Biodegradation Database. Database (Oxford). 2019, 1-11 (2019).

353. Danso, D. et al. New insights into the function and global distribution of polyethylene terephthalate (PET) degrading bacteria and enzymes in marine and terrestrial metagenomes. Appl. Environ. Microbiol. 84, e02773-17 (2018).

354. Lenz, R., Enders, K. \& Nielsen, T. G. Microplastic exposure studies should be environmentally realistic. Proc. Natl. Acad. Sci. U. S. A. 113, E4121-E4122 (2016).

355. Connors, K. A., Dyer, S. D. \& Belanger, S. E. Advancing the quality of environmental microplastic research. Environ. Toxicol. Chem. 36, 1697-1703 (2017).

356. Cunningham, E. M. \& Sigwart, J. D. Environmentally accurate microplastic levels and their absence from exposure studies. Integr. Comp. Biol. 59, 1485-1496 (2019).

357. Bucci, K., Tulio, M. \& Rochman, C. M. What is known and unknown about the effects of plastic pollution: A meta-analysis and systematic review. Ecol. Appl. 30, 1-16 (2020).

358. Beiras, R. \& Schönemann, A. M. Currently monitored microplastics pose negligible ecological risk to the global ocean. Sci. Rep. 10, 1-9 (2020).

359. Niu, Z., Vandegehuchte, M. B., Catarino, A. I. \& Everaert, G. Environmentally relevant 
concentrations and sizes of microplastic do not impede marine diatom growth. J. Hazard. Mater. 409, 124460 (2021).

360. Wang, G. X., Huang, D., Ji, J. H., Völker, C. \& Wurm, F. R. Seawater-Degradable PolymersFighting the Marine Plastic Pollution. Adv. Sci. 8, 1-26 (2021).

361. Webb, H. K., Crawford, R. J., Sawabe, T. \& Ivanova, E. P. Poly(ethylene terephthalate) polymer surfaces as a substrate for bacterial attachment and biofilm formation. Microbes Environ. 24, 39-42 (2009).

362. Bryant, J. A. et al. Diversity and Activity of Communities Inhabiting Plastic Debris in the North Pacific Gyre. mSystems 1, 1-19 (2016).

363. Wang, J. et al. Evidence of selective enrichment of bacterial assemblages and antibiotic resistant genes by microplastics in urban rivers. Water Res. 183, 116113 (2020).

364. Eckert, E. M. et al. Microplastics increase impact of treated wastewater on freshwater microbial community *. Environ. Pollut. 234, 495-502 (2018).

365. Lu, J., Zhang, Y., Wu, J. \& Luo, Y. Effects of microplastics on distribution of antibiotic resistance genes in recirculating aquaculture system. Ecotoxicol. Environ. Saf. 184, 109631 (2019). 